\title{
Modeling of Competitive Ultrasonic Assisted Removal of the Crystal Violet and Aura mineO using MWCNTs Functionalized by $\mathrm{N}-(3-n i t r o b e n z y l i d e n e)-$ N'-trimethoxysilylpropyl-ethane-1,2-diamine: Equilibrium, Kinetics and Thermodynamic Study
}

\author{
FARVEH RAOUFI, HOSSEIN AGHAEE and MAJID MONAJJEMI*
}

\author{
Department of Chemistry, Science and Research Branch, \\ Islamic Azad University, Tehran P.O.Box14515-755, Tehran, Iran \\ ${ }^{*}$ Corresponding author E-mail: $m$ _monajjemi@yahoo.com
}

http://dx.doi.org/10.13005/ojc/320412

(Received: June 15, 2016; Accepted: July 30, 2016)

\begin{abstract}
In this study, adsorbent was synthesized by covalently anchoring N-(3-nitro-benzylidene)$\mathrm{N}$-trimethoxysilylpropyl-ethane-1, 2-diamine onto multi-walled carbon nanotubes (NBATSPEDMWCNTs). This novel material was characterized by different techniques such as XRD, SEM and FT-IR.Subsequently, it was used for the ultrasound-assisted removal of Aura mine $O(A O)$ and Crystal violet (CV) from aqueous solutions was investigated. The dependency of removal percentages to variables such as $\mathrm{pH}$, initial dyes concentration, adsorbent dosage, sonication time on the removal percentages of $\mathrm{AO}$ and $\mathrm{CV}$ were simultaneously investigated by central composite design (CCD) under response surface methodology (RSM). It was shown that the adsorption of $A O$ and $C V$ follows the pseudo-second-order rate equation, while the Langmuir model explains equilibrium data. Isotherms had also been used to obtain the thermodynamic parameters such as free energy $\left(\Delta G^{\circ}\right)$, enthalpy $\left(\Delta H^{\circ}\right)$ and entropy $\left(\Delta \mathrm{S}^{\circ}\right)$ of adsorption. The negative value of $\Delta \mathrm{G}^{\circ}$ indicates the feasibility and spontaneity of the adsorption process. The positive $\Delta \mathrm{H}^{\circ}$ suggests the endothermic nature of the adsorption. The positive values of $\Delta S_{0}$ reflect the affinity of multi-walled carbon nanotubes functionalized towards CV and AO. A small amount of the adsorbent was able to remove more than $99.20 \%$ of both dyes rapidly with high adsorption capacity in binary-component system $\left(69.36 \mathrm{mgg}^{-1}\right.$ and $120.65 \mathrm{mg} \mathrm{g}^{-1}$ for $\mathrm{AO}$ and $\mathrm{CV}$ respectively).
\end{abstract}

Keywords:multi-walled carbon nanotubes, Response surface methodology, Ultrasound-assisted dye removal, Crystal Violet, Aura mine O.

\section{INTRODUCTION}

The colored dye effluents are considered to be highly toxic to the aquatic biota and affect the symbiotic process by disturbing the natural equilibrium by reducing photosynthetic activity and primary production due to the colorization of the water $^{1,2}$. Synthetic colors are widely used in food 
industries, while some of them may generate hazards and problem to human health at excess level ${ }^{3-5}$. Colors and dyes hinder from light penetration and lead to production of carcinogenic and mutagenesis hazards ${ }^{6}$. These problems make emergency to design and develop new protocol to treat them and achieve a safe and clean media ${ }^{7}$. Auramine $\mathrm{O}(\mathrm{AO})$ and its hydrochloride salt are used in the coloring of paper, textiles and leather; also as food dye ${ }^{8}$.International Agency for Research on Cancer included

$\mathrm{AO}$ is sufficient evidence of carcinogenicity in experimental animals due to its bio-transformation to reactive species in target organs of both rats and humans ${ }^{9} . \mathrm{AO}$, and its hydrochloride salts are used for coloring paper, textiles and leather ${ }^{10}$. International Agency for Research on Cancer (IARC) expressed more evidence of carcinogenicity ability of $A O$ among chemicals related to its bio-transformation to reactive species in target organs of rats and humans ${ }^{11,12}$.

As a typical cationic dye, crystal violet (CV) belongs to the triphenylmethane group, which is widely applied in coloring paper, temporary hair colorant, and dyeing cottons and wools. CV may harm the body via inhalation, ingestion and skin contact. It has also been found to cause cancer and severe eye irritation to human beings ${ }^{13-15}$. Adsorption is one of the best and simple techniques for the removal of toxic and noxious impurities in comparison to other conventional protocols like chemical coagulation, ion exchange, electrolysis, biological treatments is related to advantages viz. lower waste, higher efficiency and simple and mild operational conditions ${ }^{16-18}$. Adsorption techniques also have more efficiency in the removal of pollutants which are highly stable in biological degradation process through economically feasible mild pathways ${ }^{19-21 .}$ Of these methods, nanomaterial's based adsorbents is highly recommended for dyes pollutants removal22-26. The best figures of merit in multi component dyes systems removal are based on development of novel method that permits their accurate simultaneous determination in mixtures. The encounter difficulties are serious peaks overlapping that subsequently impossible their direct determination in mixture using general equation like Beer-Lambert ${ }^{26-28 .}$

Conventional and classical optimization protocol (one at a time) failed to give useful knowledge about the interaction between variables while requiring intensive labor and consuming long time because of requiring high number of experiments. Central composite design (CCD) under response surface methodology (RSM) can efficiently be applied for handling both variables involved and responses without suffering above-mentioned draw backs ${ }^{29-31}$.This approach enables researchers to make a suitable predicative model to apply for several factors even in the presence of complex interactions to describe responses and find the optimal conditions with less time elapsed ${ }^{32-35}$. In this work, MWCNT was modified with Schiff base-like structure following its reaction with $\mathrm{N}$-(3-nitro-benzylidene)N0-trimethoxysilylpropyl-ethane-1, 2-diamine (NBATSPED-MWCNT).A novel adsorbent followed by the characterization using different techniques such as Fourier transform infrared spectroscopy (FTIR), X-ray diffraction (XRD) and scanning electron microscopy (SEM). This adsorbent was used for the ultrasound-assisted removal of the $\mathrm{CV}$ and $\mathrm{AO}$ from aqueous solutions. The influences of variables such as sonication time, amount of adsorbent, initial CV and $\mathrm{AO}$ as well as their possible interactions were investigated and successfully optimized by central composite design (CCD) under response surface methodology (RSM). The adsorption kinetics and isotherms were also studied

\section{EXPERIMENTAL}

\section{Materials and instruments}

Auramine and Crystal violet are fully described in Table1.They were supplied from Merck (Darmstadt, Germany). The stock solution (100 $\left.\mathrm{mgL}^{-1}\right)$ of each dye was achieved following dissolution of $10 \mathrm{mg}$ of which in $100 \mathrm{~mL}$ double distilled water, separately and suitable dilute on was performed to obtain working solution with desired concentration, N-(3-(trimethoxysilyl)-propyl)ethylene diamine(TSPED) and 2-nitrobenzaldehyde (NBA) were purchased from Sigma-Aldrich. Multiwall carbon nanotubes (MWCNTs) were supplied from Riedel-de Hean (Hannover, Germany), and other reagents were used in analytical grade from Merck Company. The $\mathrm{pH}$ was adjusted and measured using $\mathrm{pH} /$ lon meter model 686 (Metronome, Switzerland, Swiss). AO and CV concentrations were determined using UV-Vis spectrophotometer model V-530 (Jasco, Japan) at wave-lengths of $434 \mathrm{~nm}$ and $588 \mathrm{~nm}$, respectively. 
The ultrasonic bath with heating system (Techno-GAZ SPA Ultrasonic System, Italy) was used at frequency $60 \mathrm{~Hz}$ and power $130 \mathrm{~W}$. The morphology of the NBATSPED-MWCNT was studied by scanning electron microscopy (SEM; HitachiS4160). The FTIR spectra of compounds were recorded on aJASCO-680 instrument in the range of $400-4000 \mathrm{~cm}^{\prime 1}$ using $\mathrm{KBr}$ pellet with ratio 1: 100 for samples to $\mathrm{KBr}$. X-ray diffraction (XRD) pattern was recorded by an automated Philips X'PertX-ray diffractometer with $\mathrm{Cu}_{\text {Ká }}$ radiation $(40 \mathrm{kV}$ and 30 $\mathrm{mA}$ ) for 2è values .The software Design-Expert@ software Version. 7.0was used for experimental design analysis and their subsequent regression analysis.

\section{Preparation of NBATSPED-MWCNT}

At first step, trimethoxysilyl propylethy -lenediamine supported on MWCNT ( $\left.\mathrm{NH}_{2}-\mathrm{MWCNT}\right)$ was synthesized by the reaction of $1.8 \mathrm{~mL} \mathrm{~N}$-(3(trimethoxysilyl)-propyl)ethylene diamine and $0.1 \mathrm{~g}$ MWCNT in $20 \mathrm{~mL}$ of dichloromethane under reflux at $40^{\circ} \mathrm{C}$ in the oil bath for 24 . Then, the obtained solid was filtered, rinsed sequentially with ethanol and dried in an oven at $50^{\circ} \mathrm{C}$. Then, $0.9 \mathrm{~g}$ of 2-nitrobenzaldehyde was added to the resulting substance in $20 \mathrm{~mL}$ of methanol and refluxed at $60^{\circ} \mathrm{C}$ in oil bath for $24 \mathrm{~h}$. The product was filtered, washed with $50 \mathrm{~mL}$ of ethanol, distilled water and then dried in oven for 10 $\mathrm{h}$ for $50^{\circ} \mathrm{C}$. In this way, N-(3-nitro-benzylidene)-NOtrimethoxysilylpropyl-ethane-1, 2-diamine supported on MWCNT (NBATSPED-MWCNT) was obtained as a new adsorbent. The steps for the synthesis of the adsorbent are presented in Scheme 1.

\section{Ultrasound-assisted multi-component adsorption of $\mathrm{AO}$ and $\mathrm{CV}$ on to NBATSPED-MWCNT}

A batch process using NBATSPED-MWCNT in presence of ultrasound was applied for binary adsorption of $\mathrm{AO}$ and $\mathrm{CV}$, while all experiments were under taken in a cylindrical glass vessel by adding $0.032 \mathrm{~g}$ of adsorbent to $50 \mathrm{~mL}$ of $\mathrm{AO}$ and $\mathrm{CVat} \mathrm{pH}$
5.0 as optimum value. The vessel was immersed in an ultrasonic bath for $4 \mathrm{~min}$ at room temperature and subsequently the solutions were centrifuged. Then, non-adsorbed dye contents were determined by using UV-Vis spectrophotometer set at wavelengths 434 and $584 \mathrm{~nm}$ for $\mathrm{AO}$ and $\mathrm{CV}$, respectively.

\section{Measurements of dye uptake}

The dye concentrations were determined from calibration curve obtained at maximum wavelength over working concentration range. The efficiency of dyes removal was determined at different experimental conditions optimized using the CCD method. The experiments were also performed in the initial dye concentration range of $5-25 \mathrm{mg}$ $\mathrm{L}^{-1}$ to obtains adsorption isotherms. The removal percentage of each dye was calculated using the following equation ${ }^{25}$ :

$$
R \%=\frac{\left(C_{\circ}-C_{t}\right)}{C_{\circ}} \times 100
$$

Where, $\mathrm{C}_{\mathrm{e}}\left(\mathrm{mg} \mathrm{L}^{-1}\right)$ and $\mathrm{C}_{\mathrm{t}}\left(\mathrm{mg} \mathrm{L}^{-1}\right)$ is the concentration of target at initial and after time $t$ respectively ${ }^{36}$.

$$
q_{e}=\frac{\left(C_{\circ}-C_{e}\right) V}{W}
$$

where $\mathrm{C}_{0}\left(\mathrm{mg} \mathrm{L}^{-1}\right)$ and $\mathrm{C}_{\mathrm{e}}\left(\mathrm{mg} \mathrm{L}^{-1}\right)$ are the initial dye concentration and equilibrium dye concentration in aqueous solution, respectively, $\mathrm{V}$ $(\mathrm{L})$ is the solution volume and W $(\mathrm{g})$ is the adsorbent mass.

\section{Central Composite Design (CCD)}

Response Surface Methodology is a statistical method that uses experimental data obtained from specified experimental design to model and optimize any process in which response of interest is influenced by several variables ${ }^{37,38}$. Primarily, this optimization is done by following three major steps, viz., performing the statistically

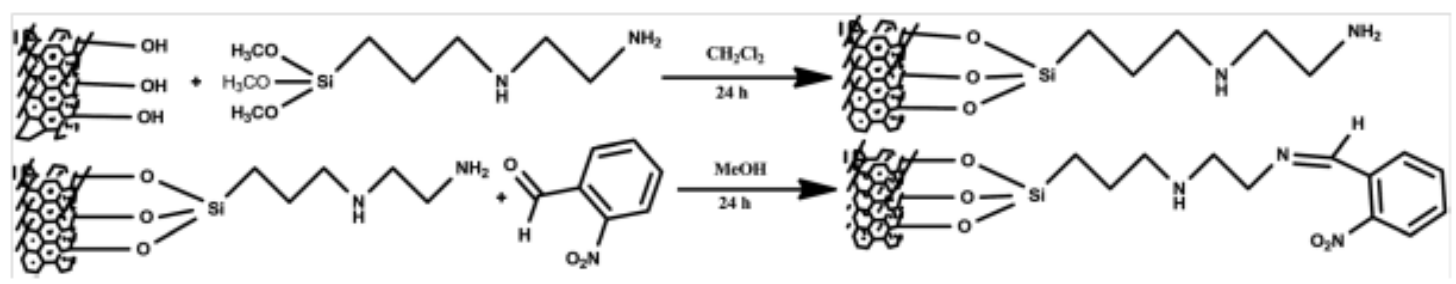

Scheme 1: 
designed experiments, estimating the coefficients in a mathematical model, and predicting their responses followed by examining the adequacy of the model $^{39}$. RSM helps to enumerate the relationships between output variables called responses $(y)$ and input variables called factors $\left(X_{i} S\right)^{40}$.

$$
y=f\left(X_{1}, X_{2}, X_{3}, \ldots X_{n}\right)
$$

CCD under RSM is suitable for fitting a quadratic surface to optimize the effective parameters and to investigate the contribution of variables and the interaction with minimum number of experiments ${ }^{41}$. Generally, the CCD consists of $2^{n}$ factorial runs with $2 n$ axial runs and $n_{C}$ central runs where $n$ is the number of variables $n=5$ in this work $)^{42}$, while the replication of central point gives a sense on numerical values of experimental errors and the data reproducibility. Thus, conducting 32 experiments permits the researchers for full study of all regions. Each experimental run was analyzed and the response was correlated with five input factors by using the following quadratic polynomial equation $^{29}$ :

$y=\beta_{\circ}+\sum_{i=1}^{5} \beta_{i} X_{i}+\sum_{i=1}^{5} \sum_{j=1}^{5} \beta_{j} X_{i} X_{j}+\sum_{i=1}^{5} \beta_{i} X_{i}^{2}+\varepsilon$

Where $y$ is the predicted response (removal percentage); $X S$ are the independent variables $A O$ and $\mathrm{CV}$ concentration, $\mathrm{pH}$, amount of adsorbent and sonication time) that are known for each experimental run. The parameter $\beta_{0}$ is the model constantâis the linear coefficient; $\beta_{i j}$ are the quadratic coefficients and $\beta_{i j}$ are the cross-product coefficients and $\beta$ is the residual term. The regression analysis is used to fit the equations for both responses to the experimental data and to estimate the statistical significance of the equation using the Design-Expert@ software Version. 7.0software.

Obtain an optimal response. The first or second-order polynomial equations obtained according to the experimental responses as well as their subsequent fitting and the analysis of variance (ANOVA) help to estimate the main contribution of variables involved and their interaction ${ }^{43}$. The plot of three-dimensional graph leads to the generation of surface response applied for the prediction of best operating conditions according to $P$-values and $F$-values. In this work, the dependence of dyes removal percentages as responses on five factors such as the initial AO concentration, initial CV concentration, $\mathrm{pH}$ effect, amount of adsorbent and sonication time at five levels (Table2) was analyzed using the software Design-Expert ${ }^{\circledR}$ software according to 32 runs.

\section{Desirability function (DF)}

Desirability function (DF) creates a function for each individual response $d_{i}$ leading to final output of global function (D), maximum value of which supports the achievement of optimum value ${ }^{44}$. The principle and application of desirability function for the best predication of real behavior of adsorption system was pointed out previously ${ }^{35}$. The desirability profiles indicate the predicted levels of variables, which produce the most desirable responses.

\section{RESULTS AND DISCUSSION}

\section{Characterization of adsorbent}

The FTIR spectrum of NBATSPEDMWCNTs (Fig 1), shows absorption peak at 1715 $\mathrm{cm}^{-1}$ corresponding to the stretching vibration of carbonyl groups. The broad peaks at $1086 \mathrm{~cm}^{-1}$ could be assigned to $\mathrm{C}-\mathrm{O}$ stretching fromphenolic, alcoholic, etheric groups and to $\mathrm{C}-\mathrm{C}$ bonds. The new peak appearing at $\approx 3400 \mathrm{~cm}^{-1}$ corresponds to $\mathrm{OH}$ stretching. This peak can be assigned to the hydroxyl group of moisture, or carboxylic groups. The aromatic $\mathrm{C}=\mathrm{C}$ stretch is observed at $\approx 1459 \mathrm{~cm}^{-1}$. The FT-IR spectrum of $\mathrm{NH}_{2}-\mathrm{MWCNT}$ displays a new peak as a weak shoulderat2931 $\mathrm{cm}^{-1}$, which corresponds to the stretching vibrations of $\mathrm{C}-\mathrm{H}$ bonds in propyl group. After the addition of 2-nitrobenzaldehyde, the new peak appeared at $1635 \mathrm{~cm}^{-1}$ is related to $\mathrm{C}=\mathrm{N}$ which indicates successful synthesis ofNBATSPED. Following the addition of NBA (Fig. 1), two peaks at 1324 and 1585 $\mathrm{cm}^{-1}$ are attributed to $-\mathrm{NO}_{2}$ groups which confirm again the success of this step ${ }^{45}$ the morphological features of the samples studied by SEMare shown in (Fig. 2).After the surface modification with NBATSPED, the NBATSPED-functionalized MWCNTs became rough, larger and bundled ${ }^{46}$. The XRD pattern of the NBATSPED-MWCNTs (Fig.3) represents a peak at 25.961 (002) corresponding to the interlayer spacing of the nanotube. The peaks at 43.05(100), 
53.92(004)and 78.5(100) correspond to diffractions and reflections from the carbon atoms ${ }^{47}$ As seen, the highly crystalline nature of theMWCNTs after functionalizing with NBATSPED is confirmed, while the high intensity of peak at 53.49 (004) shows that there has been a small amount of material in amorphous state. Theobserved XRD pattern indicates that the prepared NBATSPEDMWCNT is well-synthesized.

\section{Analysis of Central Composite Design}

As it is seen from CCD(Table2), the effects of five dependent variables $\mathrm{AO}$ concentration $\left(\mathrm{X}_{1}\right)$,
CV concentration $\left(\mathrm{X}_{2}\right), \mathrm{pH}\left(\mathrm{X}_{3}\right)$, amount of adsorbent $\left(X_{4}\right)$ and time of sonication $\left(X_{5}\right)$ were investigated. 32 experiments and their corresponding responses are presented in Table 2. Analysis (ANOVA) was performed for the removal Percentageof variance of each dye by using Design-Expert $₫$ software Version. 7.0.(Table 2) the quality of the polynomial model equation was judged statistically by the coefficient of determination $R^{2}$ and its statistical significance was determined by $F$-test. $P$-values less than 0.05 are generally considered as a criterion for distinguishing statistically significant variables. However, Bonferroni test was applied to reduce alpha value to 0.01

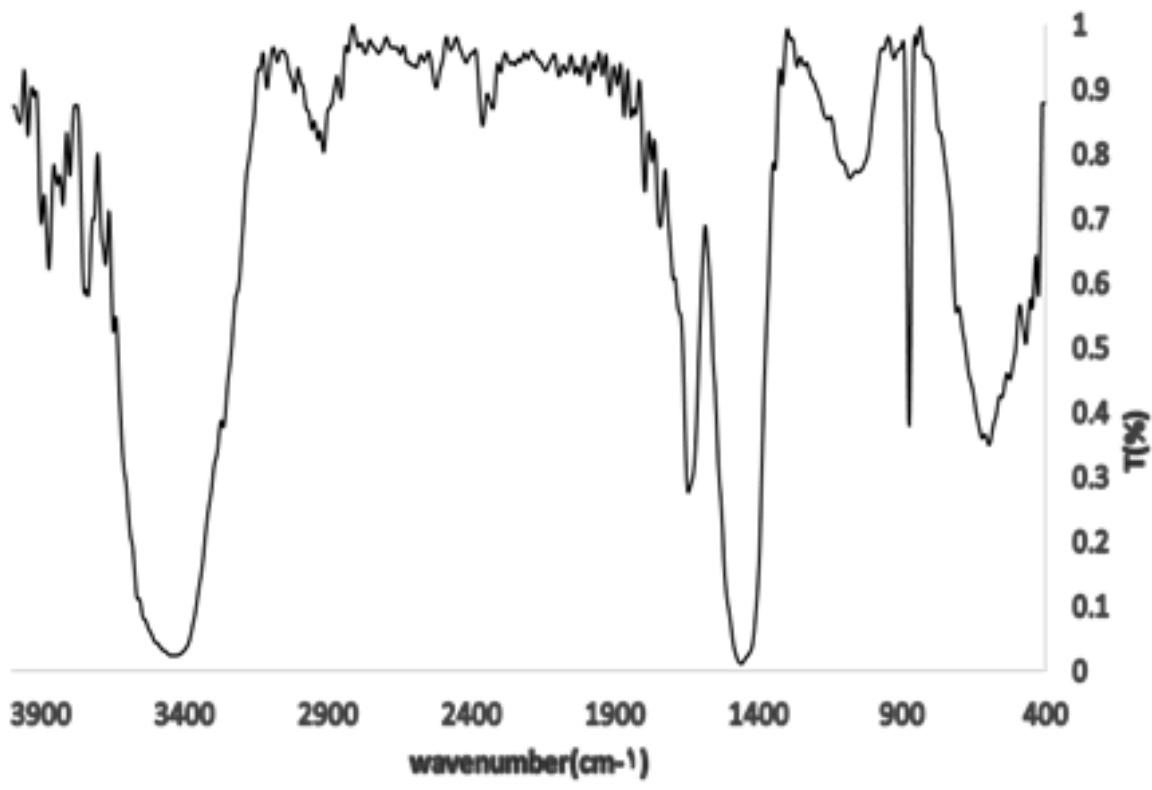

Fig.1: FT-IR, transmittance spectrum of the prepared NBATSPED-MWCNT

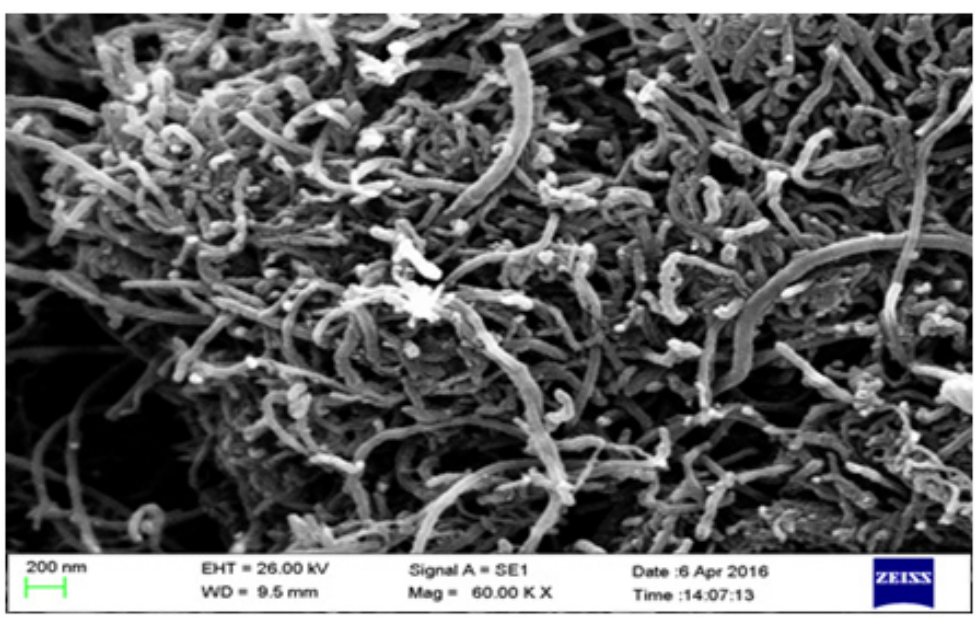

Fig. 2: The SEM image of NBATSPED-MWCNT 
which results in reducing the number of significant variables. As mentioned above, a $P$-value less than 0.01 (Bonferroni adjusted) indicates the statistical significance of each factor at $95 \%$ confidence level. Thus, the following predictive models describing the removal percentages of $(\mathrm{AO})$ and $(\mathrm{CV})$ dyes were obtained in terms of significant variables which satisfy the Bonferroni limit.

$$
\begin{aligned}
& \mathrm{R} \% \mathrm{AO}=-184.15-7.10 \mathrm{X}_{1}+28.60 \mathrm{X}_{2}+71.77 \mathrm{X}_{3}- \\
& 17611.10 X_{4}+14.44 X_{5}-0.23 X_{1} X_{2}- \\
& 1.61 X_{1} X_{3}+295.14 X_{1} X_{4}-0.34 X_{1} X_{5}- \\
& 1.77 X_{2} X_{3}+20.54 X_{2} X_{4}-2.52 X_{2} X_{5}+626.01 X_{3} X_{4} \\
& 2.40 X_{3} X_{5}+2205.68 X_{4} X_{5}+(5) 0.30 X_{1}^{2} \\
& 0.10 X_{2}^{2}-3.35 X_{3}^{2}+8679.30 X_{4}^{2}+0.25 X_{5}^{2} R \\
& \% C V=+7.64+12.58 X_{1}+14.54 X_{2}+23.92 X
\end{aligned}
$$

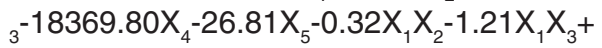

$$
\begin{aligned}
& 50.88 X_{1} X_{4}-1.13 X_{1} X_{5}-0.84 X_{2} X_{3}+119.50 X_{2} X_{4} \\
& 0.86 X_{2} X_{5}+913.10 X_{3} X_{4}+2.80 X_{3} X_{5}+ \\
& 2051.72 X_{4} X_{5}+0.14 X_{1}^{2}-0.10 X_{2}^{2}- \\
& 2.04 \mathrm{X}_{3}^{2}+53924.70 \mathrm{X}_{4}^{2}+0.16 \mathrm{X}_{5}^{2}
\end{aligned}
$$

The plot of experimental $R \%$ values versus predicted ones indicated a good fit for both $\mathrm{AO}$ and $\mathrm{CV}$ (Fig.4). From ANOVA for the $R \%_{\mathrm{AO}}$ and $R \%_{\mathrm{CV}}$, the $P$-values for the lack of fits corresponding to $A O$ and
CV were obtained to be 0.16 and 0.33 , respectively which prove the applicability of the predictive models. For both models, and adjusted were close to 1 confirming the goodness of the fit 13. From Eq. (5), it is seen that the $\mathrm{pH}$ and its interaction with both $\mathrm{AO}$ and $\mathrm{CV}$ concentrations are significant which negatively affect $R \%{ }_{A O}$. Another significant variable that positively affects $R \%_{\mathrm{AO}}$ is amount of adsorbent. The trend in Eq. (6) corresponding to $R \%_{\mathrm{AO}}$ is fairly similar to that of $\mathrm{AO}$. However, $\mathrm{CV}$ concentration significantly affects the $R \%_{\mathrm{CV}}$ negatively in linear and quadratic ways. Furthermore, the interaction of the $\mathrm{pH}$ with amount of adsorbent played significant role in $R \%{ }_{\mathrm{AO}}$ and $R \%{ }_{\mathrm{CV}}$.

\section{Response surface plots}

The 3D RSM surfaces corresponding to $R \%_{\mathrm{AO}}$ and $R \%_{\mathrm{CV}}$ were depicted and considered to optimize the significant factors and to give useful information about the possible interaction of variables. As also seen from Eqs. $(5,6)$, the effects of significant interaction terms on the curvature of the surfaces are observed as expected (Fig.5and 6). Fig (5a) shows the interaction of adsorbent dosage within initial dye concentration and their relation with removal percentage. It was seen that the removal percentage of dye decrease at higher initial dye

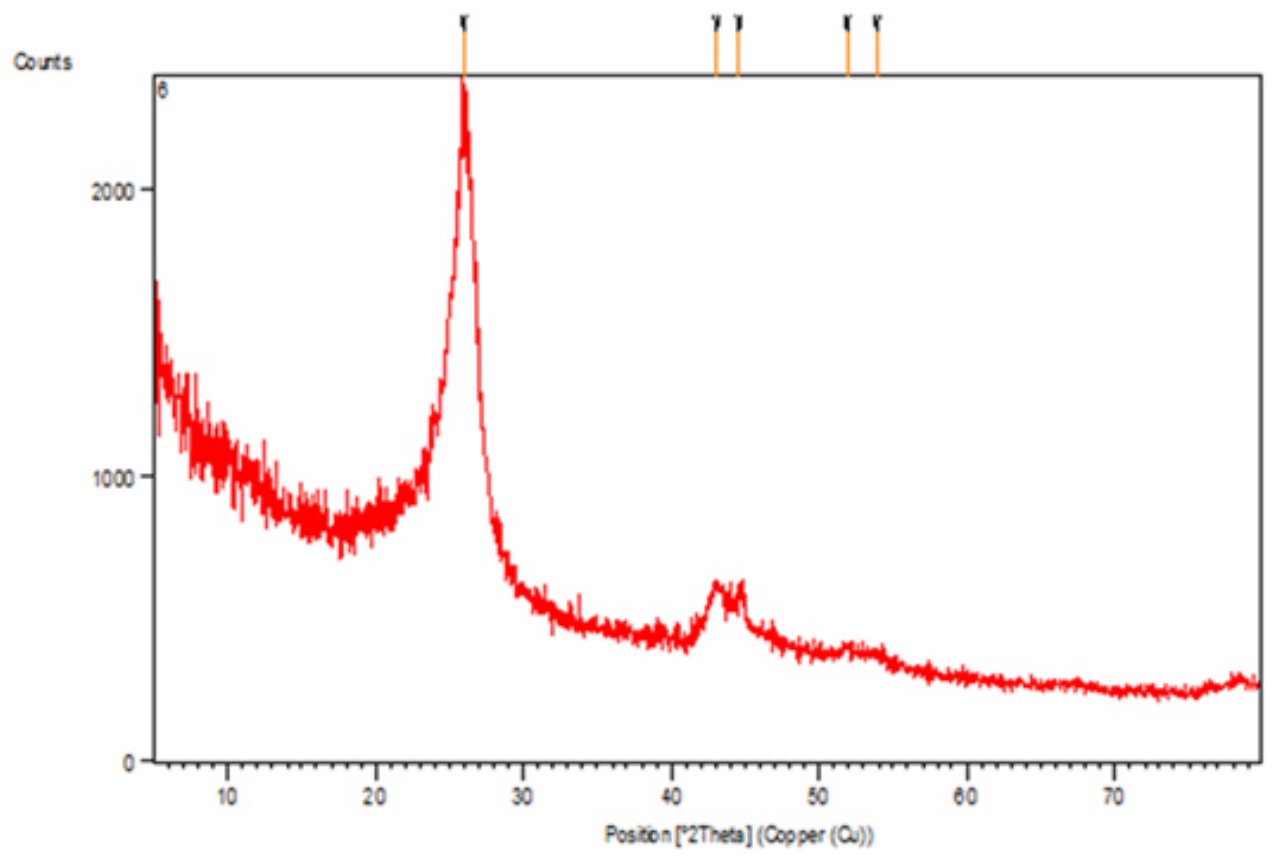

Fig. 3: XRD pattern of NBATSPED-MWCNT 

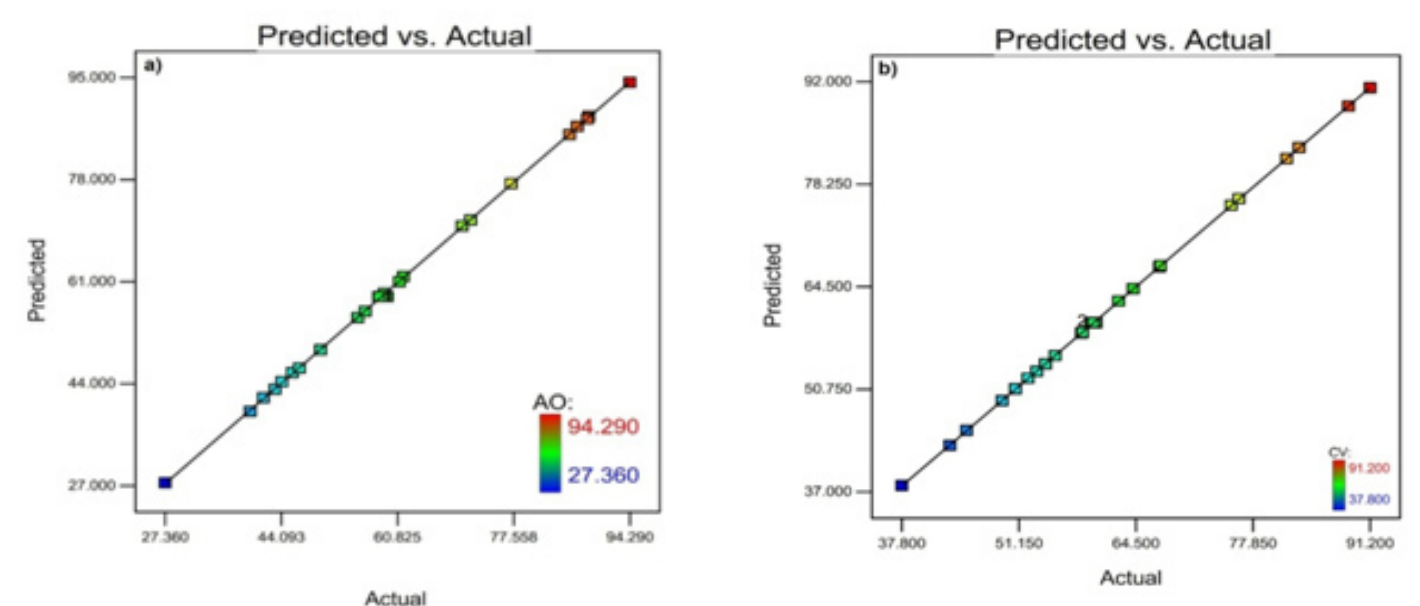

Fig. 4: The experimental data versus predicted data for removal of $\mathrm{AO}(\mathrm{a})$ and $\mathrm{CV}(\mathrm{b})$
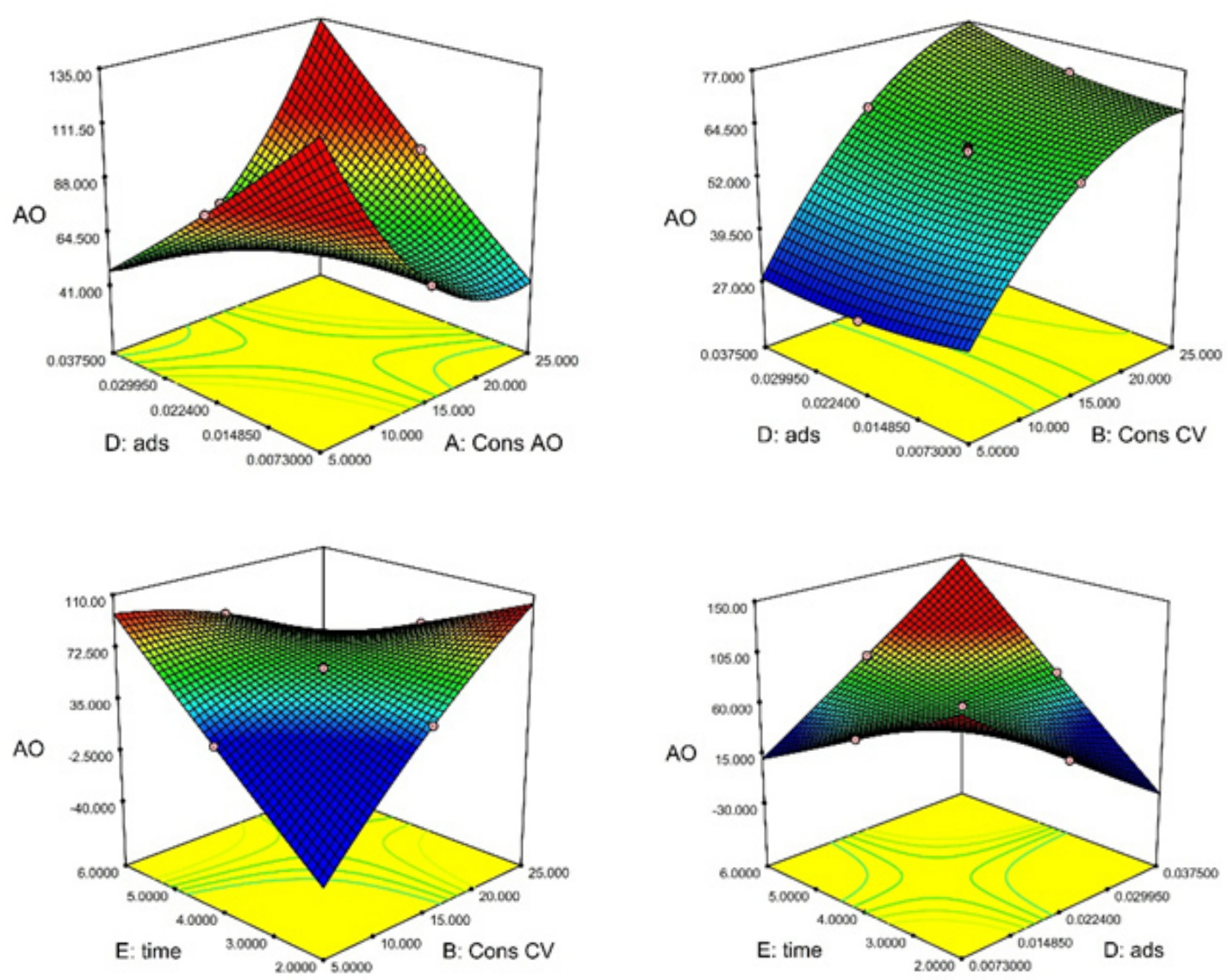

Fig. 5: Response surfaces for the dyes removal: (a) initial (AO) concentration-adsorbent dosage (b) initial (CV) concentration- adsorbent dosage; (c) initial (CV) concentration- sonication time,

(d) sonication time - adsorbent dosage 

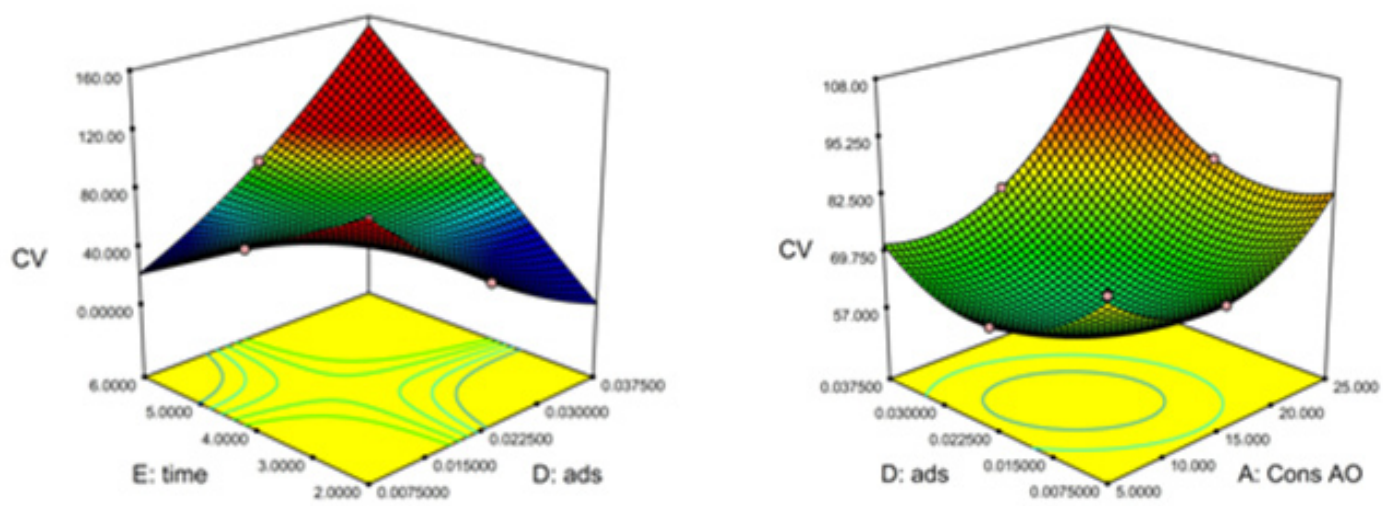

Fig. 6: Response surfaces for the dyes removal: (a) sonication time adsorbent dosage(b) adsorbent dosage -initial (CV) concentration

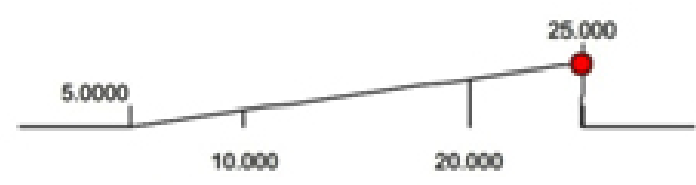

AO Concentration $\left(\mathrm{mg} \mathrm{L}^{-1}\right)=\mathbf{2 5 . 0 0}$
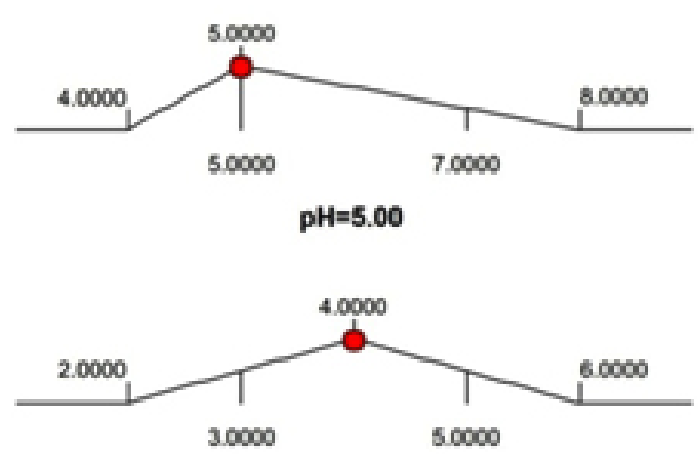

Sonication time $(\mathrm{min})=4.00$

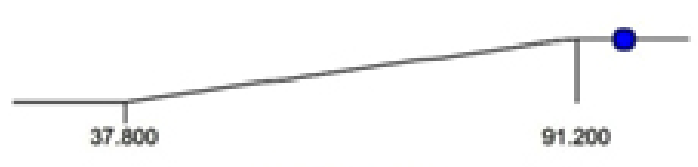

$R \%$ CV $=96.746$

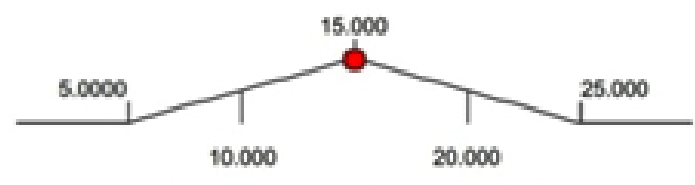

CV Concentration ( $\left.\mathrm{mg} \mathrm{L}^{-1}\right)=15.00$

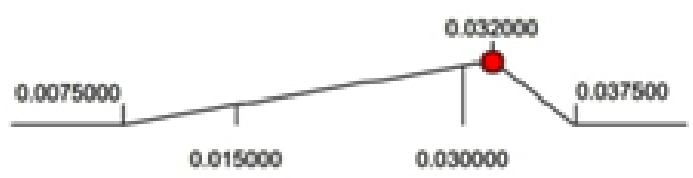

Adsorbent dosage $=0.032 \mathrm{~g}$

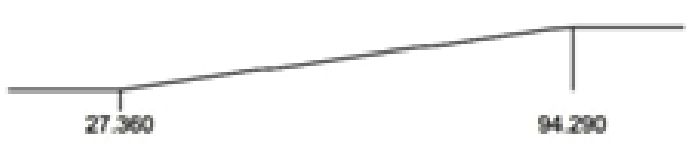

$R \%$ AO=113.03

Fig. 7: Profiles for predicated values and desirability function for removal percentage of $A O$ and $C V$. Dashed line indicates current values after optimization 
Table 1: Properties of the dyes

\begin{tabular}{lcc}
\hline Properties & Auramine O (AO) & Crystal violet(CV) \\
\hline Color index number & 41000 & 42.555 \\
CAS number & $2465-27-2$ & $548-62-9$ \\
Chemical formula & $\mathrm{C}_{17} \mathrm{H}_{21} \mathrm{~N}_{3} \cdot \mathrm{HCl}$ & $\mathrm{C}_{25} \mathrm{H}_{30} \mathrm{~N}_{3} \mathrm{Cl}$ \\
Molecular weight $\left(\mathrm{g} \mathrm{mol}^{-1}\right)$ & 303.83 & 407.979 \\
Maximum wavelength $\left(\ddot{e}_{\text {max }}, \mathrm{nm}\right)$ & 434 & 584 \\
\hline
\end{tabular}

concentration. This was also because of increase in the ratio of dye molecules to available adsorption surface area.

Fig (6a) shows the three dimensional response surface of the combined effect of weight and initial concentration on percentage removal with increase in initial concentration, removal decreases when weight of NBATSPED - MWCNT is kept constant. This is because at constant weight of NBATSPED - MWCNT when initial concentration of dye is increasing adsorbent gets saturated and it cannot adsorb further. Whereas with increase in weight of

NBATSPED - MWCNT percent removal increases monotonously. The reason is that when weight of NBATSPED - MWCNT is more, then the surface area available is also high, that increases the percentage removal.

The response surfaces plots Fig. $6 b$ demonstrated the removal percentage dependency as a function of adsorbent dosage and contact time, the removal percentage increased with enhance in adsorbent dosage due to its high specific surface area and small particle size. At higher value probably due to increase in surface area and availability of more active adsorption sites the rate of adsorption significantly increased. At lower amount of NBATSPED - MWCNT, due to insufficiency of reactive sites and lower ratio of dye molecule to vacant site removal percentage significantly decreased.

\section{Optimization of CCD by DF for extraction procedure}

The profile for desirable option with predicted values in the Design-Expert software was used for the optimization of the process (Fig.7). The desirability in the range of 0.0 (undesirable) to 1.0 (very desirable) was used to obtain a global function $(D)$ that is the base of optimization. Based on these calculations and desirability score of 1.0, maximum removal (100 and $97.00 \%$ for $\mathrm{AO}$ and $\mathrm{CV}$, respectively)was obtained at optimum conditions as: $4 \mathrm{~min}$ for sonication time, $0.032 \mathrm{~g}$ for adsorbent mass, $25 \mathrm{mgL}^{-1}$ for $\mathrm{AO}$ and $15 \mathrm{mgL}^{-1}$ for $\mathrm{CV}$ at $\mathrm{pH}$ 5.0. Five solutions with different amounts of ideal conditions were used to predict the optimum conditions for $A O$ and $C V$ dyes adsorption on to NBATSPED-MWCNT. The validity of the predicated responses at the optimized conditions was checked by performing duplicate experiments at similar conditions with RSD lower than $2 \%$ and removal percentage more than $97.5 \%$ in good agreement with the predicted value. This strong agreement proves that the predictive model found based on RSM is well applicable for describing the removal percentages of dyes studied against the variables involved.

\section{Adsorption equilibrium study}

Adsorption equilibrium isotherm is designed based on mathematical relation of the amount of adsorbed target per gram of adsorbent $\left(\mathrm{q}_{\mathrm{e}}\left(\mathrm{mgg}^{-1}\right)\right)$ to the equilibrium non-adsorbed amount of dye in solution $\left(\mathrm{C}_{\mathrm{e}}\left(\mathrm{mgL}^{-1}\right)\right.$ at fixed temperature ${ }^{48,49}$. Isotherm studies are divided to well-known models such as Langmuir, Freundlich, Temkin and DubininRadushkevich based on well-known conditions. The Langmuir model is the most frequently employed model given by following equation ${ }^{50}$ :

$$
q_{e}=\frac{Q_{m} K_{L} C_{e}}{1+K_{L} C_{e}}
$$

Where $C_{e}, Q_{m}$ and $K_{L}$ are the concentration of adsorbate at equilibrium ( $\left.\mathrm{mgL}^{-1}\right)$, maximum 
monolayer adsorption capacity $\left(\mathrm{mgg}^{-1}\right)$ and Langmuir constant $\left(\mathrm{Lmg}^{-1}\right)$, respectively. $\mathrm{C}_{\mathrm{e}} / \mathrm{q}_{\mathrm{e}}$ was plotted against $\mathrm{C}_{\mathrm{e}}$ where parameters such $\mathrm{asQ}_{\mathrm{m}}, K_{\mathrm{L}}$, and $R^{2}$ were calculated based on the slope and intercept of such lines and displayed in Table4. The values of
$K_{\mathrm{a}}$ (the Langmuir adsorption constant $\left.\left(\mathrm{Lmg}^{-1}\right)\right)$ and $Q_{m}$ (theoretical maximum adsorption capacity $\left(\mathrm{mgg}^{-1}\right)$ ) were obtained from the intercept and slope of the plot of $\mathrm{C}_{\mathrm{e}} / \mathrm{q}_{\mathrm{e}}$ ver. $C_{\mathrm{e}}$, respectively. The applicability of Langmuir modelfor the interpretation of the

Table 2: Experimental factors and levels in the central composite design

\begin{tabular}{|c|c|c|c|c|c|c|c|}
\hline \multirow[t]{2}{*}{ Factors } & & \multicolumn{6}{|c|}{ LevelsStar point $\alpha=2.0$} \\
\hline & & Low (-1) & Central (0) & $\operatorname{High}(+1)$ & $-\alpha$ & $+\alpha$ & \\
\hline \multicolumn{2}{|c|}{$\left(\mathrm{X}_{1}\right) \mathrm{AO}$ Concentration $\left(\mathrm{mg} \mathrm{L}^{-1}\right)$} & 10 & 15 & 20 & 5 & 25 & \\
\hline \multicolumn{2}{|c|}{$\left(\mathrm{X}_{2}\right) \mathrm{CV}$ Concentration $\left(\mathrm{mg} \mathrm{L}^{-1}\right)$} & 10 & 15 & 20 & 5 & 25 & \\
\hline$\left(X_{3}\right) \mathrm{pH}$ & 5.0 & 6.0 & 7.0 & 4.0 & 8.0 & & \\
\hline \multirow{2}{*}{\multicolumn{2}{|c|}{$\begin{array}{l}\left(X_{4}\right) \text { Adsorbent mass }(g) \\
\left(X_{5}\right) \text { Sonication time }(\mathrm{min})\end{array}$}} & 0.0150 & 0.0225 & 0.0300 & 0.0075 & 0.0375 & \\
\hline & & 3.0 & 4.0 & 5.0 & 2.0 & 6.0 & \\
\hline \multirow[t]{2}{*}{ Experiment } & \multirow{2}{*}{$\begin{array}{c}\text { Factors } \\
\mathbf{X}_{1}\end{array}$} & & & & \multicolumn{3}{|c|}{ Response (R \%) } \\
\hline & & $X_{2}$ & $X_{3}$ & $X_{4}$ & $X_{5}$ & AO & $\mathrm{CV}$ \\
\hline 1 & 20 & 10 & 5.0 & 0.03 & 5 & 94.290 & 81.700 \\
\hline 2 & 15 & 15 & 6.0 & 0.0225 & 4 & 58.700 & 59.900 \\
\hline 3 & 15 & 15 & 6.0 & 0.0225 & 4 & 58.130 & 59.800 \\
\hline 4 & 15 & 15 & 6.0 & 0.0375 & 4 & 61.700 & 76.250 \\
\hline 5 & 15 & 15 & 6.0 & 0.0225 & 4 & 58.120 & 59.700 \\
\hline 6 & 15 & 15 & 6.0 & 0.0225 & 4 & 58.190 & 59.650 \\
\hline 7 & 5 & 15 & 6.0 & 0.0225 & 4 & 88.350 & 62.530 \\
\hline 8 & 15 & 15 & 6.0 & 0.0225 & 4 & 58.250 & 59.450 \\
\hline 9 & 15 & 15 & 6.0 & 0.0075 & 4 & 58.900 & 67.300 \\
\hline 10 & 15 & 15 & 6.0 & 0.0225 & 2 & 41.500 & 45.190 \\
\hline 11 & 15 & 15 & 6.0 & 0.0225 & 4 & 59.350 & 59.610 \\
\hline 12 & 15 & 25 & 6.0 & 0.0225 & 4 & 70.140 & 64.190 \\
\hline 13 & 15 & 15 & 8.0 & 0.0225 & 4 & 45.690 & 52.190 \\
\hline 14 & 15 & 15 & 6.0 & 0.0225 & 6 & 77.190 & 75.360 \\
\hline 15 & 20 & 20 & 7.0 & 0.015 & 3 & 61.090 & 55.300 \\
\hline 16 & 10 & 20 & 5.0 & 0.03 & 5 & 85.600 & 88.750 \\
\hline 17 & 20 & 20 & 5.0 & 0.015 & 5 & 49.750 & 53.190 \\
\hline 18 & 10 & 20 & 7.0 & 0.015 & 5 & 56.170 & 58.410 \\
\hline 19 & 15 & 15 & 6.0 & 0.0225 & 4 & 58.910 & 59.800 \\
\hline 20 & 25 & 15 & 6.0 & 0.0225 & 4 & 86.700 & 83.110 \\
\hline 21 & 15 & 15 & 6.0 & 0.0225 & 4 & 58.650 & 59.390 \\
\hline 22 & 10 & 20 & 7.0 & 0.03 & 3 & 55.120 & 58.310 \\
\hline 23 & 15 & 15 & 6.0 & 0.0225 & 4 & 58.350 & 59.710 \\
\hline 24 & 20 & 20 & 5.0 & 0.03 & 3 & 71.360 & 67.190 \\
\hline 25 & 20 & 10 & 7.0 & 0.015 & 5 & 46.700 & 54.180 \\
\hline 26 & 15 & 15 & 6.0 & 0.0225 & 4 & 58.600 & 59.950 \\
\hline 27 & 15 & 5 & 6.0 & 0.0225 & 4 & 27.360 & 37.800 \\
\hline 28 & 15 & 15 & 4.0 & 0.0225 & 4 & 44.190 & 50.750 \\
\hline 29 & 20 & 10 & 7.0 & 0.03 & 3 & 43.190 & 49.250 \\
\hline 30 & 10 & 10 & 7.0 & 0.03 & 5 & 88.190 & 91.200 \\
\hline 31 & 10 & 10 & 5.0 & 0.015 & 3 & 39.620 & 43.280 \\
\hline
\end{tabular}




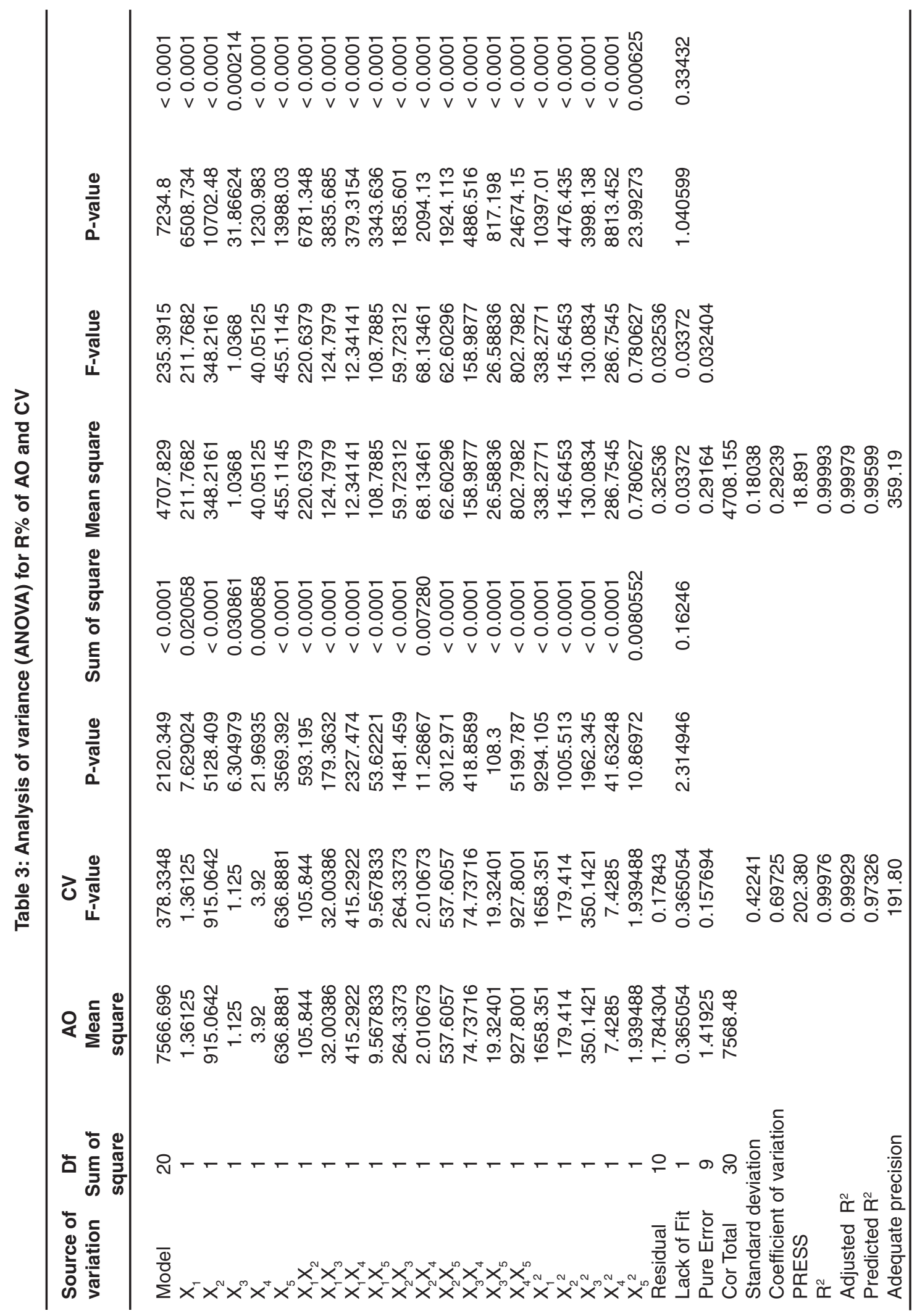


Table 4: Various isotherm constants and their correlation coefficients calculated for the adsorption of AO and CV on toNBATSPED-MWCNT

\begin{tabular}{|c|c|c|c|}
\hline Dye & & AO & CV \\
\hline Amount of adsorbent & & $0.02 \mathrm{~g}$ & $0.02 \mathrm{~g}$ \\
\hline Isotherm & Parameters & Value & \\
\hline \multirow[t]{3}{*}{ Langmuir } & $\mathrm{Qm}\left(\mathrm{mg} \cdot \mathrm{g}^{-1}\right)$ & 69.36 & 120.65 \\
\hline & $\mathrm{Ka}\left(\mathrm{L} \mathrm{mg}^{-1}\right)$ & 0.852 & 0.213 \\
\hline & $\mathrm{R} 2$ & 0.990 & 0.990 \\
\hline \multirow[t]{3}{*}{ Freundlich } & $1 / n$ & 0.321 & 0.639 \\
\hline & $\mathrm{K}_{\mathrm{F}}\left(\mathrm{L} \mathrm{mg}^{-1}\right)$ & 3.96 & 4.95 \\
\hline & $\mathrm{R} 2$ & 0.93 & 0.97 \\
\hline \multirow[t]{3}{*}{ Temkin } & $\mathrm{B}_{1}$ & 15.36 & 30.28 \\
\hline & $\mathrm{K}_{\mathrm{T}}\left(\mathrm{L} \mathrm{mg}^{-1}\right)$ & 10.36 & 5.39 \\
\hline & $\mathrm{R}^{2}$ & 0.94 & 0.95 \\
\hline \multirow[t]{4}{*}{ Dubinin-Radushkevich } & Qs $\left(\mathrm{mg} \mathrm{g}^{-1}\right)$ & 55.23 & 70.19 \\
\hline & $\mathrm{B} \times 10^{-7}$ & -1 & -1 \\
\hline & E & 2272.72 & 2272.72 \\
\hline & $\mathrm{R}^{2}$ & 0.96 & 0.93 \\
\hline
\end{tabular}

Table 5: Various Kinetic constants and their correlation coefficients calculated for the adsorption of AO and CV onto NBATSPED-MWCNT

\begin{tabular}{|c|c|c|c|c|c|c|c|c|c|c|}
\hline \multicolumn{3}{|l|}{ Model } & \multicolumn{3}{|c|}{ Parameters } & \multicolumn{2}{|c|}{ AO $\left(20 \mathrm{mg} \mathrm{L}^{-1}\right)$} & \multicolumn{3}{|c|}{ CV $\left(10 \mathrm{mg} \mathrm{L}^{-1}\right)$} \\
\hline \multirow{3}{*}{\multicolumn{3}{|c|}{ pseudo-First-orderkinetic }} & \multirow{3}{*}{\multicolumn{3}{|c|}{$\begin{array}{l}\mathrm{k}_{1}\left(\min ^{-1}\right) \\
\mathrm{q}_{\mathrm{e}}(\text { calc })\left(\mathrm{mg} \mathrm{g}^{-1}\right) \\
\mathrm{R}^{2}\end{array}$}} & \multicolumn{2}{|c|}{0.521} & \multicolumn{3}{|c|}{0.326} \\
\hline & & & & & & \multirow{2}{*}{\multicolumn{2}{|c|}{$\begin{array}{l}7.96 \\
0.82\end{array}$}} & \multicolumn{3}{|c|}{6.32} \\
\hline & & & & & & & & \multirow{2}{*}{\multicolumn{3}{|c|}{$\begin{array}{c}0.90 \\
0.145\end{array}$}} \\
\hline \multirow{3}{*}{\multicolumn{3}{|c|}{ pseudo-Second-orderkinetic }} & \multirow{3}{*}{\multicolumn{3}{|c|}{$\begin{array}{l}\mathrm{k}_{2}\left(\mathrm{~min}^{-1}\right) \\
\mathrm{q}_{\mathrm{e}}(\mathrm{calc})\left(\mathrm{mg} \mathrm{g}^{-1}\right) \\
\mathrm{R}^{2}\end{array}$}} & \multicolumn{2}{|c|}{0.101} & \multirow{2}{*}{\multicolumn{3}{|c|}{$\begin{array}{l}0.145 \\
20.36\end{array}$}} \\
\hline & & & & & & \multicolumn{2}{|c|}{26.39} & & & \\
\hline & & & & & & \multicolumn{2}{|c|}{0.984} & \multicolumn{3}{|c|}{0.993} \\
\hline \multirow{3}{*}{\multicolumn{3}{|c|}{ Intraparticlediffusion }} & \multirow{2}{*}{\multicolumn{3}{|c|}{$\begin{array}{l}\mathrm{K}_{\text {diff }}\left(\mathrm{mg} \mathrm{g}^{-1} \mathrm{~min}^{-1 / 2}\right) \\
\mathrm{C}\left(\mathrm{mg} \mathrm{g}^{-1}\right)\end{array}$}} & \multirow{2}{*}{\multicolumn{2}{|c|}{3.69}} & \multicolumn{3}{|c|}{2.56} \\
\hline & & & & & & \multirow{2}{*}{\multicolumn{2}{|c|}{$\begin{array}{l}6.23 \\
0.94\end{array}$}} & \multirow{2}{*}{\multicolumn{2}{|c|}{$\begin{array}{l}4.26 \\
0.96\end{array}$}} & \\
\hline & & & \multicolumn{3}{|c|}{$R^{2}$} & & & \\
\hline \multirow{3}{*}{\multicolumn{3}{|c|}{ Elovich }} & \multirow{2}{*}{\multicolumn{3}{|c|}{$\begin{array}{l}\beta\left(\mathrm{g} \mathrm{mg}^{-1}\right) \\
\alpha\left(\mathrm{mg} \mathrm{g}^{-1} \mathrm{~min}^{-1}\right)\end{array}$}} & \multicolumn{2}{|c|}{0.63} & & & \\
\hline & & & & & & \multirow{2}{*}{\multicolumn{2}{|c|}{$\begin{array}{c}396.58 \\
0.86\end{array}$}} & \multicolumn{3}{|c|}{263.39} \\
\hline & & & \multicolumn{3}{|c|}{$\mathrm{R}^{2}$} & & & & 92 & \\
\hline \multicolumn{3}{|c|}{$\mathrm{q}_{\mathrm{e}(\exp )}\left(\mathrm{mg} \mathrm{g}^{-1}\right)$} & & & & \multicolumn{2}{|c|}{21.32} & & & \\
\hline Dye & & & AO & & & & & cV & & \\
\hline Temperature (K) & 288.15 & 308.15 & 318.15 & 328.15 & 338.15 & 288.15 & 308.15 & 318.15 & 328.15 & 338.15 \\
\hline$\Delta \mathrm{G}^{\circ}\left(\mathrm{kj} \mathrm{mol}^{-1}\right)$ & -5.137 & -7.673 & -9.792 & -11.998 & -11.02 & -3.802 & -4.643 & -5.724 & -6.313 & -8.834 \\
\hline$\Delta \mathrm{H}^{\circ}\left(\mathrm{kj} \mathrm{mol}^{-1}\right)$ & & & 43.216 & & & & & 29.15 & & \\
\hline$\Delta \mathrm{S}^{\circ}\left(\mathrm{j} \mathrm{mol}^{-1} \mathrm{k}^{-1}\right)$ & & & 197.32 & & & & & 150.55 & & \\
\hline
\end{tabular}


experimental data over the whole concentration range is proven from high correlation coefficient at all adsorbent masses. The increase in the amount of adsorbent leads to significant enhancement in the actual amount of adsorbed dye. The parameters of Freundlich isotherm model such as $K_{\mathrm{F}}$ and the capacity of the adsorption were calculated from the intercept and slope of the linear plot of $\ln q_{\mathrm{e}}$ versus $\ln C_{\mathrm{e}}$, respectively ${ }^{51}$. The heat of the adsorption and the adsorbent-adsorbate interaction were evaluated by using Temkin isotherm model ${ }^{52}$. In this model, $B$ is the Temkinconstant related to heat of the adsorption $\left(\mathrm{Jmol}^{-1}\right), T$ is the absolute temperature $(\mathrm{K}), R$ is the universal gas constant $\left(8.314 \mathrm{Jmol}^{-1} \mathrm{~K}^{-1}\right)$ and $K$ is the equilibrium binding constant $\left(\mathrm{Lmg}^{-1}\right)$. D-R model was applied to estimate the porosity apparent free energy and the characteristic of adsorption ${ }^{53}$. In this model $B\left(\mathrm{~mol}^{2} / \mathrm{K}^{2}\right)$ is a constant related to the adsorption energy, $Q_{S}\left(\mathrm{mgg}^{-1}\right)$ is the theoretical saturation capacity and $E$ is the Polanyi potential. The slope of the plot of $I n q_{e}$ versus $\mu^{2}$ gives $B$ and its intercept yields the $Q_{S}$ value. The linear fit between the plot of $\mathrm{C}_{\mathrm{e}} / \mathrm{q}_{\mathrm{e}}$ versusC $\mathrm{C}_{\mathrm{e}}$ and calculated correlation coefficient $\left(R^{2}\right)$ for Langmuir isotherm model shows that the dye removal isotherm can be better represented by Langmuir model (Table4). This confirms that the adsorption of $\mathrm{AO}$ and CVdyes takes place at specific homogeneous sites as a monolayer on to the NBATSPED-MWCNT surface.

\section{Kinetic study}

Adsorption of a solute by a solid in aqueous solution through complex stages ${ }^{54}$ is strongly influenced by several parameters related to the state of the solid (generally with very heterogeneous reactive surface) and to physico- chemical conditions under which the adsorption occurred. The rate of dyes adsorption onto adsorbent was fitted to traditional models like, pseudo-first, second-order, intra-particle and Elovich models. The Lagergren pseudo-first order modeled scribed the adsorption kinetic data ${ }^{55}$. The Lagergren is commonly expressed as follows:

$$
\frac{d q_{t}}{d t}=k_{1}\left(q_{s}-q_{t}\right)
$$

Where, $\mathrm{q}_{\mathrm{t}}$ and $\mathrm{dq}_{\mathrm{t}}\left(\mathrm{mgg}^{-1}\right)$ are the adsorption capacities at equilibrium and time $t$, respectively. $k_{1}$ is the rate constant of the pseudo-first-order adsorption $\left(\operatorname{Lmin}^{-1}\right)$. The log $\left(q_{e}{ }^{\prime} q_{t}\right)$ versus $t$ was plotted and the values of $\mathrm{k}_{1}$ and $\mathrm{q}_{\mathrm{e}}$ were determined by using the slope and intercept of the line, respectively ${ }^{56}$.

$$
\log \left(q_{e}-q_{t}\right)=\log q_{t}-\left(\frac{k_{1}}{2.303}\right) t
$$

The fact that the intercept is not equal toq $_{e}$ imply that there action is unlikely to follow the first-order ${ }^{57}$. The relationship between initial solute concentration and rate of adsorption is linear when pore diffusion limits the adsorption process. Therefore, it is necessary to fit experimental data to another model (Table5) such as pseudo-second order model ${ }^{58}$, based on the following equation:

$$
\frac{d q_{t}}{d t}=k_{2}\left(q_{c}-q_{t}\right)^{2}
$$

Eq.(11) is integrated over the interval 0 to $t$ for $t$ and 0 to $\mathrm{q}_{\mathrm{t}}$ for $\mathrm{q}_{\mathrm{e}}$ to give

$$
\frac{t}{q_{t}}=\frac{1}{k_{2} q_{e}^{2}}+\frac{t}{q_{e}}
$$

As mentioned above, the plot oflog $\left(q_{\mathrm{e}}-q_{\mathrm{t}}\right)$ versus $t$ does not show good results for entire sorption period, while the plot of $t / q_{t}$ versus $t$ shows a straight line. The values of $k_{2}$ and equilibrium adsorption capacity $q_{e}$ were calculated from the intercept and slope of the plot of $t / q$ versus $t$ (Table5). The calculated $\mathrm{q}_{\mathrm{e}}$ values at different working conditions like various initial dyes concentrations and/or adsorbent masses were close to the experimental data and higher $R^{2}$ values corresponding to this model confirm its more suitability for the explanation of experimental data. This indicates that the pseudo-second-order kinetic model applies better for the adsorption of $\mathrm{AO}$ and $\mathrm{CV}$ system for the entire sorption period the intraparticle diffusion equation is given as ${ }^{59}$ :

$$
q_{t}=k_{d i f} t^{t / 2}+C
$$

Where $k_{\text {dif }}$ is the intraparticle diffusion rate constant $\left(\mathrm{mg} /\left(\mathrm{g} \cdot \mathrm{min}^{1 / 2}\right)\right)$ and $C$ shows the boundary layer thickness. The linear form of Elovich model is generally expressed $\mathrm{as}^{60}$ : 


$$
q_{t}=\frac{1}{\beta} \ln (\alpha \beta)+\frac{1}{\beta} \ln t
$$

The kinetic data from pseudo-first and pseudo-second-order adsorption kinetic models as well as the intraparticle diffusion and Elovich model are given in Table5. The linear plots oft $/ q_{t}$ versus $t$ indicated a good agreement between the experimental and calculatedq $\mathrm{e}_{\mathrm{e}}$ values for different initial dyes concentrations. Furthermore, the correlation coefficients of the pseudo-second-order kinetic model $\left(R^{2}>0.99\right)$ were greater than that of the pseudo-first-order model $\left(R^{2}<0.95\right)$. As a result, the adsorption fits to the pseudo-second-order better than the pseudo-first-order kinetic model.

\section{Theoretical approach}

In this work we have modeled some parts of our systems based on works ${ }^{61-197}$ and we will start a theoretical calculation for any further research in this area.

\section{Thermodynamic studies}

The thermodynamic parameters, the values of enthalpy $\left(\Delta \mathrm{H}^{0}\right)$, and entropy $\left(\Delta \mathrm{S}^{\circ}\right)$, and Gibbs free energy $\left(\Delta G^{0}\right)$, of the sorption are useful in defining whether the sorption reaction is endothermic or exothermic and spontaneity of the adsorption process ${ }^{55}$ the adsorption standard free energy changes $\left(\Delta \mathrm{G}^{0}\right)$ can be calculated according to ${ }^{198}$ :

$$
\Delta G^{\circ}=-R T \operatorname{Ln} K \text { 。 }
$$

Where, $\mathrm{R}\left(8.314 \mathrm{Jmol}^{-1} \mathrm{~K}^{-1}\right)$ is the ideal gas constant, and $\mathrm{T}(\mathrm{K})$ is the temperature. The negative values at different temperatures were due to the fact that the adsorption process is spontaneous. The value of decreased with an increase in temperature, indicated that the spontaneous nature of the adsorption of $\mathrm{AO}$ and $\mathrm{CV}$ dyes is inversely proportional to the temperature. The values of other parameters such as enthalpy change and entropy change may be determined from Van't Hoff equation ${ }^{199}$ :

$$
\operatorname{Ln} K=\frac{\Delta S^{\circ}}{R}-\frac{\Delta \mathrm{H}^{\circ}}{R T}
$$

The Thermodynamic parameters are listed in Table 6. A positive standard enthalpy change suggests that the interaction of $\mathrm{AO}$ and $\mathrm{CV}$ by NBATSPED-MWCNT isendothothermic, which supported by the incresing feasibility adsotption $A O$ and $C V$ with the increase in temperature towards NBATSPED-MWCNT.

\section{Comparison of various adsorbent}

The performance of the proposed method has been compared with other adsorbents (Table7). The adsorption capacity and contact time for our work are superior to other adsorbents to removal AO. The results indicated that the ultrasound-assisted removal method has are mark able ability to improve the efficiency of dyes removal. The ultrasonicassisted enhancement of dye removal could be attributed to the high-pressure shock wave sand high speed micro jets during the violent collapse of cavitation bubbles.

\section{CONCLUSION}

It is observed from the present study that the NBATSPED-MWCNT under the sonication is an efficient, fast and sensitive adsorption method for the removal of $A O$ and $C V$. The influences of experimental parameters on the dyes removal percentages were investigated by experimental design methodology (RSM). The adsorption characteristic was examined with the variations of $\mathrm{pH}$, sonication time, NBATSPED-MWCNTdosage, initial $A O$ and $C V$ concentration. The removal of $A O$ and $\mathrm{CV}$ from aqueous solutions in short time (4 min) is feasible with high removal percentage at optimum $\mathrm{pH}$ (5.0) which is neutral and is an advantage for the adsorption process. The equilibrium data were best described by the Langmuir model. The process kinetics can be success fully fitted with pseudosecond order model Thermodynamic constants were evaluated using equilibrium constants changing with temperature. The negative values of $\Delta G^{\circ}$ indicate the spontaneity and positive values of $\Delta \mathrm{H}^{\circ}$ showed the endothermic nature of $\mathrm{AO}$ and $\mathrm{CV}$ sorption. The data and methodology presented in this paper might be useful for designing the adsorbent for the treatment of actual effluent. Furthermore, the results of this study encourage the researches and industries to use ultrasound devices for more efficient dye 
adsorption. The optimized method was successfully applied to real wastewater samples.

\section{ACKNOWLEDGEMENT}

The author expresses their appreciation to the Science and Research Branch Islamic Azad University, Tehran, Iran for financial support of this work.

\section{REFERENCES}

1. Yao L., Zhang L., Wang R., Chou S., Dong Z., J Hazard Mater,2016, 301, 462-470.

2. Kim S.Y., Jin M.R., Chung C.H., Yun Y.S., Jahng K.Y., Yu K.Y., , J Biosci Bioeng, 2015,119, 433-439.

3. Mahmoodi N.M., Soltani-Gordefaramarzi S., Sadeghi-Kiakhani M., Environmental monitoring and assessment, 2013,185, 10235-10248.

4. Kaushik P., Malik A., Environmental science and pollution research international,2013, 20 , 2882-2892.

5. Wang L., Environmental science and pollution research international, 2013, 20 , 46354646.

6. Mittal A., J Hazard Mater, 2006,133 , 196202.

7. V.V. Pathak, R. Kothari, A.K. Chopra, D.P. Journal of environmental management, 2015, 163 , 270-277.

8. Asfaram A., Ghaedi M., Simultaneous determination of cationic dyes in water samples with dispersive liquid-liquid microextraction followed by spectrophotometry: experimental design methodology, New Journal of Chemistry, (2016).

9. Asfaram A., Ghaedi M., Goudarzi A., Soylak M., RSC Advances,2015, 5,39084-39096.

10. Mall I.D.,. Srivastava V.C,. Agarwal N.K, Journal of Hazardous materials,2007 143, 386-395.

11. Jamshidi M., Ghaedi M., Dashtian K., Hajati S., Bazrafshan A.A., Ultrasonics Sonochemistry,2016 32, 119-131.

12. Shukla N.B., Madras G., Journal of Applied Polymer Science,2012, 124 , 3892-3899.

13. Dil E.A., Ghaedi M., Ghaedi A., Asfaram A., Jamshidi M., Purkait M.K., Journal of the Taiwan Institute of Chemical Engineers, 2016, 59, 210-220.
14. Asfaram A., Ghaedi M., Hajati S., Goudarzi A., RSC Advances,2015, 5, 72300-72320.

15. Pourjavadi A.,. Nazari M, Hosseini S.H., RSC Advances,2015, 5 , 32263-32271.

16. Li H., An N., Liu G., J. Li, N. Liu, M. Jia, W. Zhang, X. Yuan, J Colloid Interface Sci,2016, 466, 343-351.

17. Saratale R.G., Sivapathan S.S., W J.J.,. Kim H.Y, Saratale G.D., Kim D.S., Part A, Toxic/ hazardous substances \& environmental engineering,2016, 51,164-177.

18. Luan J., -X P.. Hou, Liu C., Shi C., X G.-. Li, Cheng H.-M., Journal of Materials Chemistry A,2016, $4,1191-1194$.

19. Agarwal S., Tyagi I., Gupta V.K., Dastkhoon M., Ghaedi M., Yousefi F., Asfaram A., Journal of Molecular Liquids,2016, 219, 332-340.

20. Ghaedi M., Ghaedi A.M., dehghanian n., dashtian k., Physical Chemistry Chemical Physics, 2016.

21. Mazaheri H., Ghaedi M., Asfaram A., Hajati S., Journal of Molecular Liquids,2016, 219 , 667-676.

22. Ghaedi M., Khafri H.Z.,. Asfaram A, Goudarzi A., Spectrochimica Acta Part A: Molecular and Biomolecular Spectroscopy, 2016, 152 , 233-240.

23. Azad F.N., Ghaedi M., Asfaram A., Jamshidi A., Hassani G., Goudarzi A., Azqhandi M.H.A., Ghaedi A., RSC Advances,2016, 6 , 19768-19779.

24. Agarwal S., Tyagi I., Gupta V.K., Bagheri A.R., Ghaedi M., Asfaram A.,. Hajati S, Bazrafshan A.A., Journal of Environmental Chemical Engineering,2016, 4 ,1769-1779.

25. Asfaram A., Ghaedi M., Yousefi F., Dastkhoon M., Ultrasonics Sonochemistry,2016, 33 (2016) 77-89.

26. Roosta M., Ghaedi M., Asfaram A., RSC Advances, 2015, 5, 57021-57029. 
27. Asfaram A, Ghaedi M., Goudarzi A.,. Rajabi M, Dalton Transactions, 2015, 44, 1470714723.

28. Hajati S., Ghaedi M., Mahmoudi Z., Sahraei R., Part A, Molecular and biomolecular spectroscopy,2015,150, 1002-1012.

29. Lee S.L.,. Liew S.W, Ong S.T., Acta chimica Slovenica, 2016,63, 144-153.

30. Tehrani M.S., Zare-Dorabei R., Spectrochimica Acta Part A: Molecular and Biomolecular Spectroscopy,2016,160, 8-18.

31. Asfaram A., Ghaedi M., Hajati S., Goudarzi A., Bazrafshan A.A., Spectrochimica Acta Part A: Molecular and Biomolecular Spectroscopy,2015, 145, 203-212.

32. Dastkhoon M., Ghaedi M., Asfaram A., Goudarzi A., Langroodi S.M., Tyagi I., Agarwal S., Gupta V.K., Response surface optimization, Separation and Purification Technology,2015, 156, Part 2 , 780-788.

33. Bazrafshan A.A, Hajati S., Ghaedi M., RSC Advances,2015, 5 , 79119-79128.

34. Das P., Banerjee P., Mondal S., Environmental science and pollution research international,2015,22, 1318-1328.

35. Chowdhury S., Chakraborty S., Saha P.D., Environmental science and pollution research international,2013, $20,1698-1705$.

36. Elwakeel K.Z., El-Bindary A.A., El-Sonbati A.Z., Hawas A.R., RSC Advances,2016, 6 , 3350-3361.

37. Ansari F., Ghaedi M., Taghdiri M.,. Asfaram A, Experimental design and derivative spectrophotometry method, Ultrasonics Sonochemistry,2016, 33 , 197-209.

38. Asfaram A., Ghaedi M.,. Azqhandi M.H.A, Goudarzi A., Dastkhoon M., RSC Advances,2016, 6, 40502-40516.

39. Dil E.A., Ghaedi M., Ghaedi A.M., Asfaram A., Goudarzi A., Hajati S., Soylak M., Agarwal S.,. Gupta V.K, Journal of Industrial and Engineering Chemistry,2016, 34 , 186-197.

40. Bagheri A.R., Ghaedi M., Hajati S., Ghaedi A.M.,. Goudarzi A, Asfaram A., RSC Advances,2015, 5 ,59335-59343.

41. Azad F.N., Ghaedi M., Dashtian K., Hajati S., Pezeshkpour V., Ultrasonics Sonochemistry,2016, 31 (2016) 383-393.

42. Jamshidi M., Ghaedi M., Dashtian K., Ghaedi A.M.,. Hajati S, Goudarzi A.,. Alipanahpour
E, Spectrochimica acta. Part A, Molecular and biomolecular spectroscopy,2016, 153, 257-267.

43. Ghaedi M.,. Khafri H.Z, Asfaram A., Goudarzi A., Spectrochimica acta. Part A, Molecular and biomolecular spectroscopy, 2016,152 , 233-240.

44. Roosta M., Ghaedi M.,. Daneshfar A, Darafarin S., Sahraei R., Purkait M.K., Ultrason Sonochem,2014, $21,1441-1450$.

45. Waldron R., Physical Review,1955, 99 , 1727.

46. Nasiri Azad F., Ghaedi M., Dashtian K., Montazerozohori M., Hajati S., Alipanahpour E., RSC Advances,2015, 5 , 61060-61069.

47. Naeimi H., Rahmatinejad S., Nazifi Z.S., Journal of the Taiwan Institute of Chemical Engineers, 2016, 58 , 1-7.

48. Ioannou Z., Simitzis J., journal of the International Association on Water Pollution Research, 2013,67 ,1688-1694.

49. Lim C.K., Bay H.H., Neoh C.H., Aris A., Abdul Majid Z., Ibrahim Z., Environmental science and pollution research international,2013, 20 ,7243-7255.

50. Langmuir I., Journal of the American Chemical Society,1918, 40 1361-1403.

51. Freundlich U., Die adsorption in lusungen, (1906).

52. Temkin M., Pyzhev V., Recent modifications to Langmuir isotherms, (1940).

53. Dubinin M., Serpinsky V., Carbon, 19 (1981) 402-403.

54. Maghsoudi M., Ghaedi M., Zinali A., Ghaedi A.M,. Habibi M.H, Spectrochimica Acta Part A: Molecular and Biomolecular Spectroscopy,2015, 134 (2015) 1-9.

55. El-Bindary A.A., El-Sonbati A.Z., AlSarawy A.A., Mohamed K.S., Farid M.A., Spectrochimica acta. Part A, Molecular and biomolecular spectroscopy,2014,136PC ,1842-1849.

56. HoY.-S, McKay G. , Water research,2000, 34, 735-742.

57. Dawood S., Sen T.K., Water research,2012, 46, 1933-1946.

58. HoY.-S, McKay G., Process biochemistry,1999, 34 , 451-465.

59. Weber W.J., Morris J.C., Journal of the Sanitary Engineering Division,1963, 89 , 31- 
60.

60. Yang Y., Wang G., Wang B., Li Z., Jia X., Zhou Q., Zhao Y., Bioresource technology, 2011,102, 828-834.

61. Mollaamin, F.; Baei, MT.; Monajjemi, M.; Zhiani, R.; Honarparvar, B.; Russian Journal of Physical Chemistry A, Focus on Chemistry, 2008, 82 (13), 2354-2361

62. Monajjemi, M. Chemical Physics. 2013, 425, 29-45

63. Monajjemi, M.; Heshmat, M.; Aghaei, H.; Ahmadi, R.; Zare, K. Bulletin of the Chemical Society of Ethiopia, 2007,21 (1)

64. Monajjemi, M.;Honarparvar, B. H. ; Haeri, H. ; Heshmat ,M.; Russian Journal of Physical Chemistry C. 2006, 80(1):S40-S44

65. Monajjemi, M.; Ketabi, S.; Amiri, A. Russian Journal of Physical Chemistry, 2006, 80 (1), S55-S62

66. Yahyaei, H.; Monajjemi, M.; Aghaie, H.; K. Zare, K. Journal of Computational and Theoretical Nanoscience. 2013, 10, 10, 2332-2341

67. Mollaamin, F.; Gharibe, S.; Monajjemi, M. Int. J. Phy. Sci, 2011, 6, 1496-1500

68. Monajjemi, M.; Ghiasi, R.; Seyed Sadjadi, M.A.Applied Organometallic Chemistry,2003,17, 8, 635-640

69. Monajjemi, M.; Wayne Jr, Robert. Boggs, J.E. Chemical Physics.2014, 433, 1-11

70. Monajjemi, M.; Sobhanmanesh, A.; Mollaamin, F. Fullerenes, Nanotubes, and Carbon Nanostructures, 2013, 21 47-63

71. Monajjemi, M.; Mollaamin, F. Journal of Computational and Theoretical Nanoscience, 2012, 9 (12) 2208-2214

72. Monajjemi, M.; Honarparvar, B.; Nasseri, S. M. .; Khaleghian M. Journal of Structural Chemistry. 2009, 50, 1, 67-77

73. Monajjemi, M.; Aghaie, H.; Naderi, F. Biochemistry (Moscow).2007,72 (6), 652657

74. Ardalan, T.; Ardalan, P.; Monajjemi, M. Fullerenes, Nanotubes, and Carbon Nanostructures, 2014, 22: 687-708

75. Mollaamin, F.; Monajjemi, M.; Mehrzad, J. Fullerenes, Nanotubes, and Carbon Nanostructures. 2014, 22: 738-751

76. Monajjemi, M.; Najafpour, J.; Mollaamin, F. Fullerenes, Nanotubes, and Carbon
Nanostructures. 2013, 21(3), 213-232

77. Monajjemi, M.; Karachi, N.; Mollaamin, F. Fullerenes, Nanotubes, and Carbon Nanostructures, 2014, 22: 643-662

78. Yahyaei, H.; Monajjemi, M. Fullerenes, Nanotubes, and Carbon Nanostructures.2014, 22(4), 346-361

79. Monajjemi, M. Falahati, M.; Mollaamin, F.; Ionics, 2013, 19, 155-164

80. Monajjemi, M.; Mollaamin, F. Journal of Cluster Science, 2012, 23(2), 259-272

81. Tahan, A.; Monajjemi, M. Acta Biotheor,2011, 59, 291-312

82. Lee, V.S.; Nimmanpipug, P.; Mollaamin, F.; Kungwan, N.; Thanasanvorakun, S.; Monajjemi, M. Russian Journal of Physical Chemistry A, 2009, 83, 13, 2288-2296

83. Monajjemi, M.; Heshmat, M.; Haeri, HH, Biochemistry (Moscow), 2006, 71 (1), S113S122

84. Monajjemi, M.; Yamola, H.; Mollaamin, F.Fullerenes, Nanotubes, and Carbon Nanostructures, 2014, 22, 595-603

85. Mollaamin, F.; Layali, I.; Ilkhani A. R.; Monajjemi, M. African Journal of Microbiology Research .2010, 4(24) 2795-2803

86. Mollaamin, F.; Shahani poor, p K. .; Nejadsattari, T. ; Monajjemi, M. African Journal of Microbiology Research. 2010, 4(20) 2098-2108

87. Monajjemi, M.; Ahmadianarog, M. Journal of Computational and Theoretical Nanoscience. 2014, 11(6), 1465-1471

88. Monajjemi, M.; Jafari Azan, M.; Mollaamin, F. Fullerenes, Nanotubes, and Carbon Nanostructures.2013, 21(6), 503-515

89. Mollaamin, F.; Monajjemi, M.Physics and Chemistry of Liquids .2012, 50, 5, 2012, 596-604

90. Monajjemi, M.; Khosravi, M.; Honarparvar, B.; Mollaamin, F.; International Journal of Quantum Chemistry, 2011, 111, 27712777

91. Khaleghian, M.; Zahmatkesh, M.; Mollaamin, F.; Monajjemi, M. Fullerenes, Nanotubes, and Carbon Nanostructures, 2011, 19(4): 251-261

92. Monajjemi, M.; Baheri, H.; Mollaamin, F. Journal of Structural Chemistry.2011 52(1), 54-59 
93. Mahdavian, L.; Monajjemi, M.; Mangkorntong, N. Fullerenes, Nanotubes and Carbon Nanostructures, 2009, 17 (5), 484-495

94. Monajjemi, M., Mahdavian, L., Mollaamin, F. Bull. Chem. Soc. Ethiop. 2008, 22(2), 277286

95. Monajjemi, M.; Afsharnezhad, S, Jaafari, M.R..; Mirdamadi, S..; Mollaamin, F..; Monajemi, $\mathrm{H}$. Chemistry .2008, 17(1), 55-69

96. Monajjemi, M.; Mollaamin,F.; Gholami, M. R.; Yoozbashizadeh,H.; Sadrnezhaad, S.K.; Passdar, H.; Main Group Metal Chemistry, 2003, 26, 6, 349-361

97. Monajjemi, M.; Azad ,MT.; Haeri, HH.; Zare, K.; Hamedani, Sh.; JOURNAL OF CHEMICAL RESEARCH-S.2003, (8): 454-456

98. Monajjemi, M.; Najafpour, J. Fullerenes, Nanotubes, and Carbon Nanostructures, 2014, 22(6): 575-594

99 Monajjemi, M.; Noei, M.; Mollaamin, F. Nucleosides, Nucleotides and Nucleic Acids. 2010 29(9):676-683

100. Ghiasi, R.; Monajjemi, M.Journal of Sulfur Chemistry .2007, 28, 5, 505-511

101. Monajjemi, M.; Ghiasi, R.; Abedi, A. Russian Journal of Inorganic Chemistry.2005, 50(3), 382-388

102. Monajjemi, M. .; Naderi, F.; Mollaamin, F.; Khaleghian, M. J. Mex. Chem. Soc. 2012, 56(2), 207-211

103. Monajjemi, M.; Farahani, N.; Mollaamin, F. Physics and Chemistry of Liquids, 2012, 50(2) 161-172

104. Monajjemi, M.; Seyed Hosseini, M. Journal of Computational and Theoretical Nanoscience .2013, 10(10), 2473-2477

105. Monajjemi , M.; Honaparvar , B.; Khalili Hadad ,B.; Ilkhani ,AR.; Mollaamin, F. African Journal of Pharmacy and Pharmacology .2010, 4(8), $521-529$

106. Monajjemi, M. Theor Chem Acc, 2015, $134: 77$ DOI 10.1007/s00214-015-1668-9

107. Monajjemi, M. Journal of Molecular Modeling, 2014, 20, 2507

108. Monajjemi, M.; Honarparvar, B.; Monajemi, H.; Journal of the Mexican Chemical Society, 2006, 50 (4), 143-148

109. Monajjemi, M.; Khaleghian, M.; Mollaamin, F. Molecular Simulation. 2010, 36, 11, 865-

110. Ilkhani, Ali R.; Monajjemi, M. Computational and Theoretical Chemistry.2015 1074, 19-25

111. Monajjemi, M. Biophysical Chemistry. 2015 207,114-127

112. Monajjemi, M., Moniri, E., Panahi, H.A , Journal of Chemical and Engineering Data.2001,1249-1254.

113. Mollaamin, F.; Najafpour, J.; Ghadami, S.; Ilkhani, A. R.; Akrami, M. S.; Monajjemi, M. Journal of Computational and Theoretical Nanoscience. 11 (5), 1290-1298

114. Monajjemi, M.; Ghiasi, R.; Ketabi, S.; Passdar, H.; Mollaamin, F.Journal of Chemical Research . 2004, 1, 11.

115. Monajjemi, M.; Heshmat, M.; Haeri, H.H. Biochemistry (Moscow).2006, 71, 113-122

116. Monajjemi, M.; Heshmat, M.; Aghaei, H.;Ahmadi, R.; Zare, K. Bulletin of the Chemical Society of Ethiopia. 2007, 21, 111-116

117. Monajjemi, M., Kharghanian, L., Khaleghian, M., Chegini, H.Fullerenes Nanotubes and Carbon Nanostructures.2014, 22, 8, 0.1080/1536383X.2012.717563

118. Sarasia, E.M.; Afsharnezhad, S.; Honarparvar, B.; Mollaamin, F.; Monajjemi, M.Physics and Chemistry of Liquids. 2011, 49 (5), 561-571

119. Amiri, A.; Babaeie, F.; Monajjemi, M.Physics and Chemistry of Liquids. 2008, 46, 4, 379389

120. Monajjemi, M.; Heshmat, M.; Haeri, H.H.; Kaveh, F. Russian Journal of Physical Chemistry A,2006, 80, 7, 1061-1068

121. Monajjemi, M.; Moniri, E.; Azizi, Z.; Ahmad Panahi, H. Russian Journal of Inorganic Chemistry. 2005, 50, 1, 40-44

122. Jalilian,H.; Monajjemi, M. Japanese Journal of Applied Physics. 2015, 54, 8, 08510

123. Mollaamin, F.; Monajjemi, M. Journal of Computational and Theoretical Nanoscience.2015, 12, 6, 1030-1039

124. Felegari, Z.; Monajjemi, M. Journal of Theoretical and Computational Chemistry. 2015,14, 3, 1550021

125. Monajjemi,M; Ghahremani,N; Nikmaram, R;Main group metal chemistry,2002, 25 (12), 733-738

126. Monajjemi, M; Azizi, Z; Ghavami, M; Russian journal of inorganic chemistry, 2003, 48 (10), 1551-1559 
127. Monajjemi, M; Naderi, F; Aghaie, $\mathrm{H}$; RESEARCH JOURNAL OF CHEMISTRY AND ENVIRONMENT, 2007,11 (2), 56-62

128. Keivani,M B; Zare, K; Aghaie, M; Aghaie, H; Monajjemi, M; Journal of Chemistry,2010, 7 (1), 105-110

129. Mirzaie, S; Monajjemi, M; Hakhamaneshi, MS; Fathi, F; Jamalan, M, EXCLI journal ,2013, 12, 130

130. Pournaghdy, M; Giahi, M; Bagherinia, MA; Monajjemi, M; Aghaie, H; Fluid Phase Equilibria,2011, 301 (1), 98-104

131. Rajabzadeh, H; Nourouzian, D;Alijanvand, H.H; (...), Saboury, A.A;Moosavi-Movahedi, A.A; Monajjemi, M; Journal of the Iranian Chemical Society,2011, 8 (2), 553-561

132. Monajjemi,M; Abedi, A; Passdar, H; Bulletin of the Chemical Society of Ethiopia, 2006,20 (1), 133-142

133. Monajjemi, M; Sajadi, MA; Sayadia, R; Kia, M; Ghasemi, G; Main group metal chemistry ,2005, 28 (2), 71-84

134. Bakhshi, K; Mollaamin, F; Monajjemi, M; Journal of the Korean Chemical Society,2011, 55 (1), 7-13

135. Irani, S; Monajjemi, M; Honarparvar, B; SM Atyabi, SM; Sadeghizadeh, M; International journal of nanomedicine , 2011, 6, 213

136. Shabani, M; Monajjemi, M; Aghai, H, Journal of Chemical Research Part S 2003 (5), 249251

137. Amiri, A.; Monajjemi, M.; Ketabi, S.Physics and Chemistry of Liquids2007, 45 (4), 425433

138. Shojaee, S., Monajjemi, M.Journal of Computational and Theoretical Nanoscience.2015, 12, 3, 449-458

139. Esmkhani, R.;Monajjemi, M. Journal of Computational and Theoretical Nanoscience.2015. 12, 4, 652-659

140. Monajjemi, M., Seyedhosseini, M., Mousavi, M., Jamali, Z, Journal of Computational and Theoretical Nanoscience. 2015, 23 (3), 239244

141. Ghiasi, R.; Monajjemi, M.; Mokarram, E.E.; Makkipour, P. Journal of Structural Chemistry.2008, 4 , 4, 600-605

142. Mahdavian, L.; Monajjemi, M. Microelectronics Journal. 2010,41(2-3), 142-149

143. Monajjemi, M.; Baie, M.T.; Mollaamin, F.
Russian Chemical Bulletin.2010, 59, 5, 886889

144. Bakhshi, K.; Mollaamin, F.; Monajjemi, M. Journal of Computational and Theoretical Nanoscience. 2011, 8, 4,763-768

145. Darouie, M.; Afshar, S.; Zare, K., Monajjemi, M. journal of Experimental Nanoscience.2013, 8, 4,451-461

146. Amiri, A.; Monajjemi, M.; Zare, K.; Ketabi, S.Physics and Chemistry of Liquids. 2006, 44, 4, 449-456.

147. Zonouzi, R.;Khajeh, K.; Monajjemi, M.; Ghaemi, N. Journal of Microbiology and Biotechnology. 2013, 23, 1, 7-14

148. Ali R. Ilkhani.; Majid Monajjemi, Computational and Theoretical Chemistry.2015, 1074 19-25

149. Tahan, A.; Mollaamin, F.; Monajjemi, M. Russian Journal of Physical Chemistry A, 2009, 83 (4), 587-597

150. Khalili Hadad, B.; Mollaamin, F.; Monajjemi, M, Russian Chemical Bulletin,2011, 60(2):233236

151. Mollaamin, F.; Monajjemi, M.; Salemi, S.; Baei, M.T. Fullerenes Nanotubes and Carbon Nanostructures, 2011, 19, 3, 182-196

152. Mollaamin, F.; Shahani Pour.; K., Shahani Pour, K.; ilkhani, A.R.; Sheckari, Z., Monajjemi, M Russian Chemical Bulletin , 2012 , 61(12), 2193-2198

153. Shoaei, S.M.; Aghaei, H.; Monajjemi, M.; Aghaei, M. Phosphorus, Sulfur and Silicon and the Related Elements. 2014, 189, 5; 652660

154. Mehrzad, J., Monajjemi, M., Hashemi, M , Biochemistry (Moscow).2014, 79 (1), 31-36

155. Moghaddam, N.A., Zadeh, M.S., Monajjemi, M. Journal of Computational and Theoretical Nanoscience , 2015 , Vol. 12, No. 3, doi:10.1166/jctn.2015.3736

156. Joohari, S.; Monajjemi, M, Songklanakarin Journal of Science and Technology, 2015, 37(3):327

157. Rajaian, E., Monajjemi, M., Gholami, M.R, Journal of Chemical Research - Part S, 2002, $6,1,279-281$

158. Ghassemzadeh, L., Monajjemi, M., Zare, K, Journal of Chemical Research - Part S, 2003, 4, 195-199

159. Mehdizadeh Barforushi,M.; Safari,S.; 
Monajjemi,M.;J. Comput. Theor. Nanosci. 2015, 12, 3058-3065.

160. Mollaamin,F.; Ilkhani,A.; Sakhaei,N.; Bonsakhteh,B.; Faridchehr,A.; Tohidi,S.; Monajjemi,M.; J. Comput. Theor. Nanosci. 2015, 12, 3148-3154.

161. Rahmati,H.; Monajjemi,M.; J. Comput. Theor. Nanosci.2015, 12, 3473-3481.

162. Tarlani Bashiz,R.; Monajjemi,M.; J. Comput. Theor. Nanosci.2015, 12, 3808-3816.

163. Mehrabi Nejad,A.; Monajjemi,M.; J. Comput. Theor. Nanosci. 2015, 12, 3902-3910.

164. Monajjemi,M *.; Bagheri,S.; Moosavi,M.S..; Moradiyeh,N.; Zakeri,M.;Attarikhasraghi,N.; Saghayimarouf, N.; Niyatzadeh,G.; Shekarkhand,M.;Mohammad S. Khalilimofrad, Ahmadin,H.; Ahadi,M.; Molecules 2015, 20, 21636-21657;

165. Shabanzadeh,E.; Monajjemi,M.; J. Comput. Theor. Nanosci.2015, 12, 4076-4086.

166. Elsagh,A.: Jalilian,H.;Kianpour,E.; Sadat Ghazi Mokri,H.; Rajabzadeh,M.; Moosavi,M.S.; Ghaemi Amiri,F.; Monajjemi,M.; J. Comput. Theor. Nanosci. 2015, 12, 4211-4218.

167. Faridchehr,A.; Rustaiyan, A.; Monajjemi,M.; J. Comput. Theor. Nanosci.2015, 12, 43014314.

168. Tohidi,S.; Monajjemi,M.; Rustaiyan,A.; J. Comput. Theor. Nanosci. 2015, 12, 43454351.

169. Ali Akbari Zadeh,M.; Lari,H.; Kharghanian,L.; Balali,E.; Khadivi,R.;Yahyaei,H.; Mollaamin,F.; Monajjemi,M.; J. Comput. Theor. Nanosci. 2015, 12, 4358-4367.

170. Dezfooli,S.; Lari,H.; Balali,E.; Khadivi,R.; Farzi,F.; Moradiyeh,N.; Monajjemi,M.; J. Comput. Theor. Nanosci. 2015, 12, 44784488.

171. Jalilian,H.: Sayadian,M.; Elsagh,A.; Farzi,F.; Moradiyeh,N.; Samiei Soofi,N.; Khosravi,S.; Mohammadian,N.T.; Monajjemi,M.;J. Comput. Theor. Nanosci.2015, 12, 4785-4793.
172. Farzi,F.; Bagheri,S.; Rajabzadeh,M.; Sayadian,M.; Jalilian,H.; Moradiyeh,N.; Monajjemi,M.; J. Comput. Theor. Nanosci. 2015, 12, 4862-4872.

173. Monajjemi,M.; Nayyer T. Mohammadian J. Comput. Theor. Nanosci. 2015, 12, 48954914.

174. Monajjemi, M., Chahkandi, B. Journal of Molecular Structure: THEOCHEM, 2005, 714 (1), 28, 43-60.

175. Joohari*,S.; Monajjemi, M.; Bulgarian Chemical Communications,2015, Volume 47, Number 2631 - 646.

176. Moradiyeh,N.; Zakeri, M.; Attarikhasraghi,N.; Ahadi,M.; Saghayimarouf ,N.; Niyatzadeh , G.; Mahmoodi ,Z.; Shekarkhand,M.; Ahmadin, H.; Monajjemi,M.;J. Comput. Theor. Nanosci. 2015, 12, 5395-5401.

177. Zawari, M.; Haghighizadeh, M.; Derakhshandeh,M.; Barmaki ,Z.; Farhami,N.; Monajjemi,M.; J. Comput. Theor. Nanosci.2015, 12, 5472-5478.

178. Sadatchoobeh,S.; Monajjemi,M.; J. Comput. Theor. Nanosci. 2015, 12, 5789-5795.

179. Shadmani ,N.; MehdizadehBarforushi, M.; Shakibayifar, J.; Elsagh,A.; Zare ,K.; Abbasi,Z.; Khalili1 ,M.S.; Ahmadin ,H.; Rajabzadeh,M.; Sayadian,M.; Monajjemi,M.; J. Comput. Theor. Nanosci.2016, 13, 208-219.

180. Shadmani,N.; Monajjemi,M.; Zare,K.; J. Comput. Theor. Nanosci. 2016, 13, 378387.

181. Jamali,Z.; Monajjemi,M.; J. Comput. Theor. Nanosci.2016, 13, 643-651.

182. Mirzaei ,R.; Ziglari ,A.; Elsagh,A.; Esmkhani,R.; Monajjemi, M.; J. Comput. Theor. Nanosci.2016, 13, 899-908.

183. Monajjemi, M.; Lee, V.S.; Khaleghian, M.; B. Honarparvar, B.; F. Mollaamin, F. J. Phys. Chem C. 2010, 114, 15315

184. Monajjemi, M.Struct Chem.2012, 23,551580. 